\title{
Large-Eddy Simulation of Post-Cold-Frontal Continental Stratocumulus
}

\author{
DAVID B. MECHEM \\ Atmospheric Science Program, Department of Geography, University of Kansas, Lawrence, Kansas \\ YEFIM L. KOGAN \\ Cooperative Institute for Mesoscale Meteorological Studies, University of Oklahoma, Norman, Oklahoma \\ DAVID M. SCHULTZ \\ Division of Atmospheric Sciences, Department of Physics, University of Helsinki, and Finnish Meteorological \\ Institute, Helsinki, Finland, and Centre for Atmospheric Sciences, School of Earth, Atmospheric and \\ Environmental Sciences, University of Manchester, Manchester, United Kingdom
}

(Manuscript received 10 February 2010, in final form 11 August 2010)

\begin{abstract}
Previous large-eddy simulations (LES) of stratocumulus-topped boundary layers have been exclusively set in marine environments. Boundary layer stratocumulus clouds are also prevalent over the continent but have not been simulated previously. A suite of LES runs was performed for a case of continental post-cold-frontal stratocumulus observed by the Atmospheric Radiation Measurement Program (ARM) Climate Research Facility (ACRF), located in northern Oklahoma. Comparison with fixed, ground-based sensors necessitated an Eulerian approach in which it was necessary to supply to the model estimates of synoptic-scale advection and vertical motion, particularly given the quickly evolving, baroclinic nature of the synoptic environment. Initial analyses from the Rapid Update Cycle model supplied estimates for these forcing terms.

Turbulent statistics calculated from the LES results are consistent with large-eddy observations obtained from millimeter-wave cloud radar. The magnitude of turbulence is weaker than in typical marine stratocumulus, a result attributed to highly decoupled cloud and subcloud circulations associated with a deep layer of negative buoyancy flux arising from the entrainment of warm, free-tropospheric air. Model results are highly sensitive to variations in advection of temperature and moisture and much less sensitive to changes in synoptic-scale vertical velocity and surface fluxes. For this case, moisture and temperature advection, rather than entrainment, tend to be the governing factors in the analyzed cloud system maintenance and decay. Typical boundary layer entrainment scalings applied to this case do not perform very well, a result attributed to the highly decoupled nature of the circulation. Shear production is an important part of the turbulent kinetic energy budget. The dominance of advection provides an optimistic outlook for mesoscale, numerical weather prediction, and climate models because these classes of models represent these grid-scale processes better than they do subgrid-scale processes such as entrainment.
\end{abstract}

\section{Introduction}

Boundary layer clouds exert a strong cooling effect on the large-scale radiation budget and have been identified as a leading cause of uncertainty in global climate model (GCM) estimates of future climate change scenarios (e.g., Bony and Dufresne 2005; Medeiros et al.

Corresponding author address: David B. Mechem, Atmospheric Science Program, Department of Geography, University of Kansas, 1475 Jayhawk Blvd., 213 Lindley Hall, Lawrence, KS 660457613.

E-mail: dmechem@ku.edu.
2008; Williams and Webb 2009). Marine stratocumulus and stratus are particularly noteworthy because at any given time they cover $\sim 25 \%$ of the world's oceans (Charlson et al. 1987). These extensive cloud-topped boundary layers reside in regions of subsidence off the western continental coasts and are energetically driven largely by cloud-top radiative cooling.

Cloud-topped boundary layers also accompany midlatitude synoptic disturbances. Using a combined analysis of satellite and reanalysis data, Field and Wood (2007) found that low clouds frequently accompany midlatitude baroclinic wave cyclones. Although the analysis of Field 
and Wood was restricted to the four midlatitude oceanic regions (North and South Atlantic and North and South Pacific), the Warren Cloud Atlas (Warren et al. 1986) confirms that low clouds are common over midlatitude continental regions, with average cloud amounts (defined as the frequency of occurrence times the amount when present) ranging from $9 \%$ to $16 \%$ and $6 \%$ to $9 \%$ for stratocumulus and stratus, respectively, over the central Great Plains region of the United States. These cloud amounts are in general agreement with the annual timeaveraged cloud amounts for low clouds over the same region given by Lazarus et al. (2000), who reported lowcloud amounts of $23.0 \%$ (synoptic cloud reports), $27.8 \%$ (combination of the Belfort Laser Ceilometer and MicroPulse lidar), and 21\% [International Satellite Cloud Climatology Project (ISCCP); Rossow and Schiffer (1991)]. Given the ubiquity of synoptic disturbances in the midlatitudes, these low clouds may exert a distinct radiative cooling signature similar to marine stratocumulus. Although their globally integrated effect is unknown, two significant differences between continental and marine stratocumulus reduce the radiative impact of the continental clouds. First, the albedo of the land surface (particularly when snow covered) is higher than the albedo of the ocean surface. Thus, the albedo difference between cloud and the surface will be lower over continental regions. Second, although our study considers a nocturnal cloud case, the downwelling shortwave radiation in continental clouds may be smaller relative to marine clouds, which are most widespread during the summer months.

Large-eddy simulation (LES) has long been used to investigate cloudy boundary layers in an idealized experimental framework. Deardorff (1980b) and Moeng (1986) are perhaps the seminal works applying threedimensional LES to marine stratocumulus. Countless other LES studies of stratocumulus have followed, especially noteworthy being the extensive model intercomparisons organized under the Global Energy and Water Cycle Experiment (GEWEX) Cloud Systems Study (GCSS) boundary layer working group framework (Moeng et al. 1996; Bretherton et al. 1999; Stevens et al. 2005; Ackerman et al. 2009). With the exception of studies investigating the growth of shallow cumulus convection over land (e.g., Brown et al. 2002; Zhu and Albrecht 2003; Neggers et al. 2007), the predominance of LES work has focused on maritime boundary layer clouds in barotropic (or equivalent barotropic) atmospheres. The assumption of barotropy makes a Lagrangian framework practical because it has the advantage of not requiring estimates of large-scale horizontal advection of temperature or moisture.

Mechem et al. (2010, hereafter MKS) documented a continental stratocumulus cloud system associated with the post-cold-frontal region of a midlatitude synoptic cyclone sampled by the Southern Great Plains (SGP) Atmospheric Radiation Measurement Program (ARM) Climate Research Facility (ACRF) in northern Oklahoma (Fig. 1). They employed the technique of large-eddy observations (LEOs) (Kollias and Albrecht 2000) using millimeter-wave cloud radar to characterize not only mean cloud properties, but also the transient, rapidly evolving features associated with turbulent boundary layer eddies. Cloud radar showed vertical coherent cloud structures. Variance and skewness profiles of the vertical velocity implied a cloud-layer circulation driven by cloud-top radiative cooling and decoupled from the subcloud layer. Vertical velocity variance, taken to be related to turbulent intensity, ${ }^{1}$ was small relative to typical marine stratocumulus. MKS employed upper-air soundings and initial analyses from the Rapid Update Cycle (RUC) model (Benjamin et al. 2004a,b) to characterize the thermodynamic structure and synoptic-scale forcing accompanying the cloud and turbulence structures. Cloud properties (e.g., liquid water path, cloud-top height) were strongly modulated by the synoptic-scale forcings; however, the relative importance of advection (temperature and moisture), synoptic-scale vertical velocity, and surface fluxes of heat and moisture was not clear. From the observations alone it was not possible to ascertain the leading factors that govern the structure and evolution of these cloud systems.

The spatiotemporal relationship of these clouds to the cyclone structure highlights the importance of the horizontal transport, synoptic-scale vertical motion, and surface fluxes. Investigations of continental clouds, particularly those tied to Eulerian frameworks such as the instrumented suite at the SGP ACRF, necessitate estimates of these forcings. Xu et al. (2005) and Xie et al. (2005) compared a number of cloud-resolving model simulations of midlatitude frontal systems over the ACRF with forcings constrained by the synoptic-scale budget terms in the vicinity of the ACRF. The models had some success in representing prefrontal, frontal, and postfrontal cloud and precipitation fields, but the coarse horizontal grid spacing in the models $(2-3 \mathrm{~km})$ was not able to resolve the turbulent dynamics of the boundary layer. Smaller grid spacings are necessary so as to improve fundamental understanding of the continental cloud-topped boundary layer.

\footnotetext{
${ }^{1}$ Strictly speaking, turbulent intensity is a nondimensional measure of turbulence defined by taking the square root of the vertical velocity variance, divided by the mean wind speed (Stull 1988). This quantity is problematic when considering vertical motion, since the mean vertical velocity is near zero.
} 


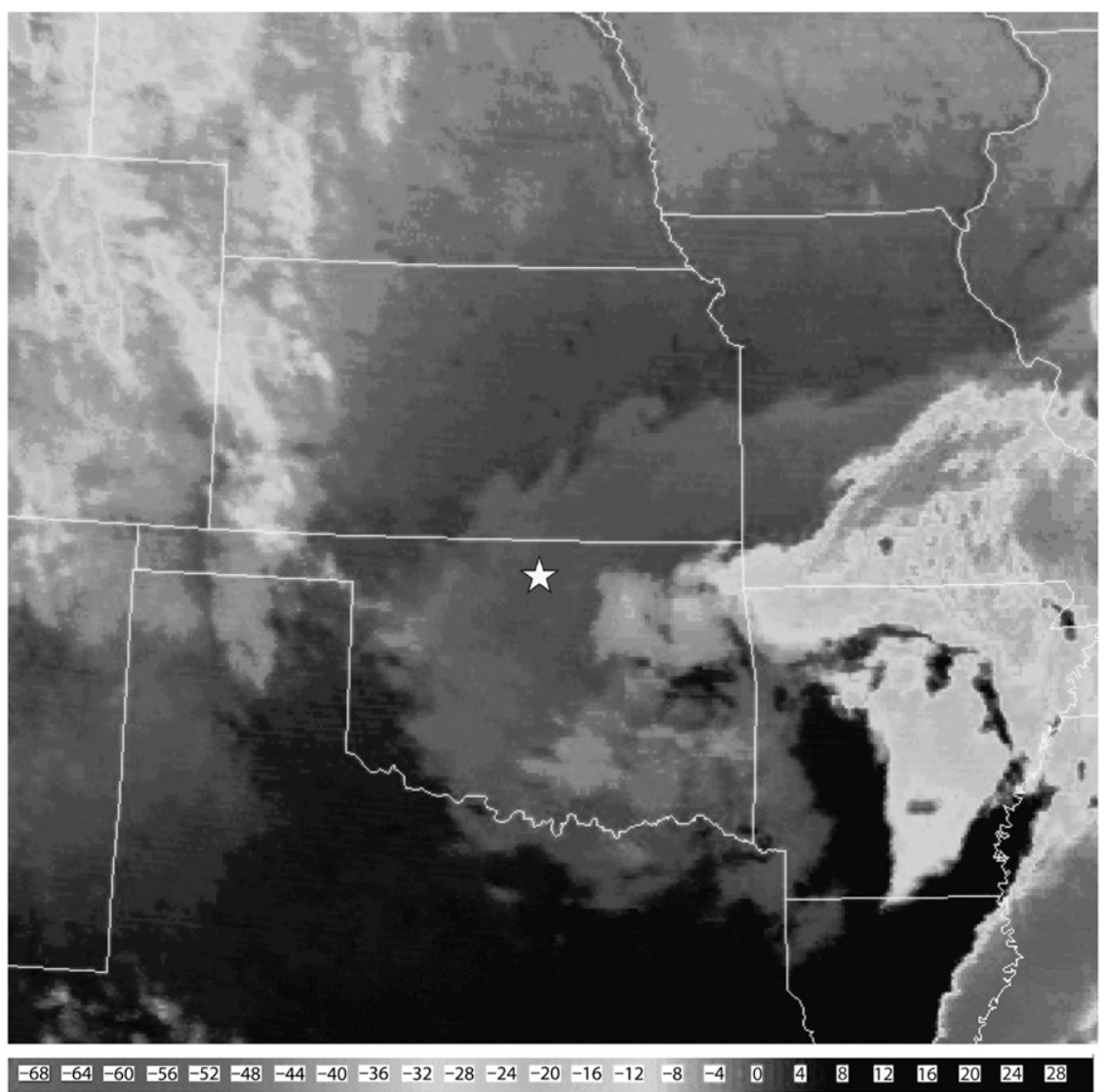

FIG. 1. GOES IR imagery for 0645 UTC 8 Apr 2006. The star represents the location of the SGP ACRF.

With this requirement in mind, we present results from a series of LES runs conducted under widely varying synoptic-scale forcing conditions. Here we apply LES to the MKS case of continental stratocumulus, located in the postfrontal region of a midlatitude synoptic disturbance. This case was chosen because of its persistence $(>9 \mathrm{~h})$ and its apparent similarity to other low-cloud systems observed over the ACRF. The overarching questions motivating our work are the following:

- To what extent does the LES capture the flow structure sampled by the cloud radar large-eddy observations?

- What are the similarities and differences between this continental case and what we know of marine cases from the multitude of oceanic LES studies in the literature?

- What processes predominantly govern the structure and evolution of continental stratocumulus clouds?

- To what degree of accuracy must we know the forcings (e.g., synoptic-scale temperature and moisture advection, and vertical velocity) in order to correctly represent continental stratocumulus in an Eulerian modeling framework?

\section{Model configuration}

All simulations were conducted using the System for Atmospheric Modeling (SAM), version 6.4 (Khairoutdinov and Randall 2003). SAM solves prognostic equations for total water and liquid water static energy and is formulated using anelastic dynamics with model variables discretized on a staggered Arakawa $\mathrm{C}$ grid. The momentum equations are integrated forward in time using a third-order Adams-Bashforth method, and the advective scheme of Smolarkiewicz and Grabowski (1990) ensures that the scalar fields remain positive definite and monotonic. The subgrid-scale model is based on the 1.5-order turbulent kinetic energy (TKE) closure model of Deardorff (1980b).

For these simulations we specify simple moist saturation adjustment for which any instantaneous supersaturation is immediately diagnosed into a condensate field. The simple treatment of microphysics neglects precipitation and any associated dynamical feedbacks, an assumption justified by the fact that the cloud system under study is nonprecipitating. Although recent work has drawn attention to the importance of cloud droplet sedimentation, even for nonprecipitating clouds (Ackerman 

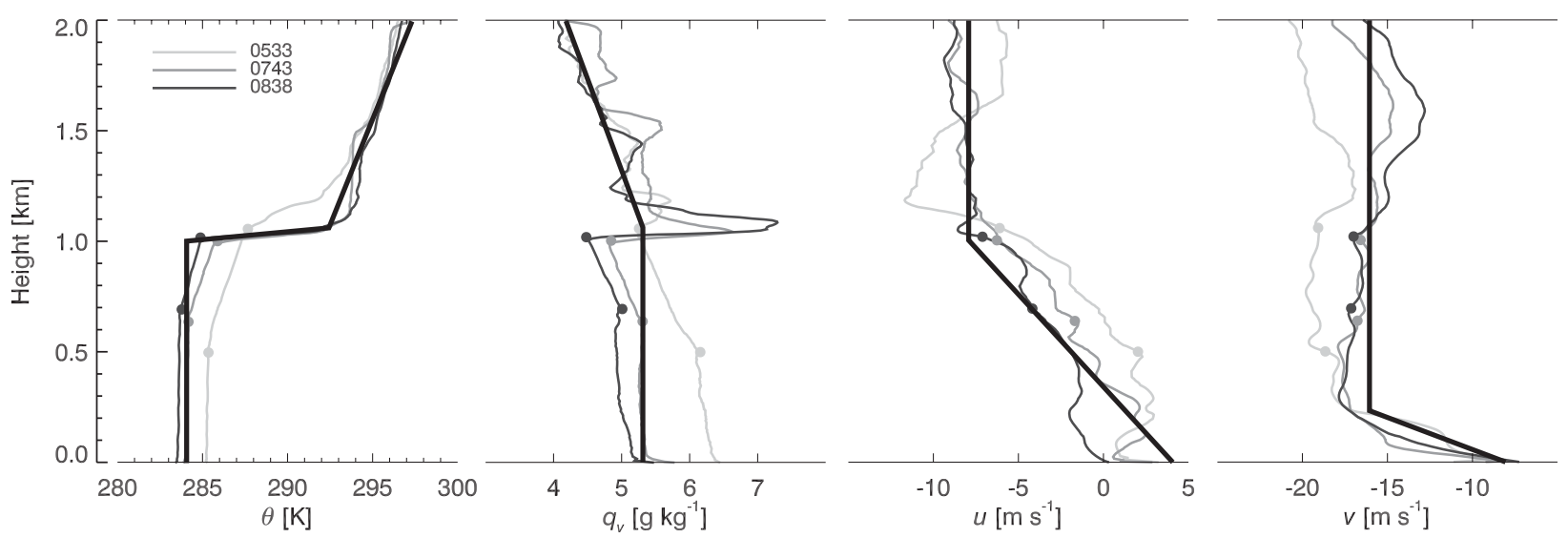

FIG. 2. Soundings of potential temperature, water vapor mixing ratio, and wind components taken at the ACRF Central Facility at the indicated times (UTC) on 8 Apr 2006. Note that LST $=$ UTC $-6 \mathrm{~h}$. Solid circles represent estimates of cloud base and cloud top for each sounding time. Thick black lines represent the idealized sounding (formulated using liquid water potential temperature $\theta_{l}$ and total water $q_{t}$ ) that serves as the model initial condition.

et al. 2004; Bretherton et al. 2007) we neglect sedimentation as being of secondary importance relative to the strong baroclinic forcings (temperature and moisture advection) and a hypothesized greater relative sensitivity of entrainment to other effects such as model grid spacing at the inversion. The cloud is furthermore assumed to be composed solely of liquid droplets. Although the top of the cloud at times reaches temperatures as low as $-1^{\circ} \mathrm{C}$, very few ice phase particles will be nucleated at temperatures this high.

The simulation takes place during nocturnal conditions, and longwave radiative transfer was calculated every time step using the two-stream, broadband, mixed-emissivity approach from Herman and Goody (1976), as applied in Wyant et al. (1997) and Khairoutdinov and Kogan (1999).

Simulations are performed on a $128 \times 128 \times 128$ grid with a horizontal grid spacing of $35 \mathrm{~m}$ and a time step of $1 \mathrm{~s}$. This grid configuration gives a horizontal domain size of $4.4 \times 4.4 \mathrm{~km}^{2}$. Although undoubtedly too small in area to resolve the mesoscale variability present in the radar observations (MKS), this configuration results in statistics virtually identical to a $512 \times 512$ simulation with 16 times the area. The model employs a stretched grid in the vertical, ranging from $10 \mathrm{~m}$ at the surface to $18 \mathrm{~m}$ in the middle of the boundary layer, and is reduced to $10 \mathrm{~m}$ in the range of the inversion (960-1300 m). Although other studies (Bretherton et al. 1999; Stevens et al. 2005) have found that vertical grid spacings of $5 \mathrm{~m}$ or less are required to correctly represent entrainment, sensitivity simulations show that finer grid spacings make very little difference in this particular case. Lateral boundary conditions are periodic, and the top boundary at $2 \mathrm{~km}$ is a rigid lid. To damp spurious waves and reflections off the top boundary, a Rayleigh damping (sponge) layer is applied over the top $25 \%$ of the model domain. All simulations are run for six hours, with most of the statistics evaluated over the 3-4-h and 5-6-h periods.

\section{a. Initial conditions and forcing for the control simulation}

Our simulations are based on the low-cloud system accompanying the surface cyclone that passes over the ACRF on 7-8 April 2006. These low clouds appear in the IR imagery largely as horizontally homogeneous and only slightly colder than the underlying surface (Fig. 1). We are predominantly interested in the period from 0600 to 1000 UTC when the cloud system was nonprecipitating and evolving rather slowly (Fig. 2 in MKS). Figure 2 illustrates three successive soundings taken during the time period of interest. The soundings generally indicate a well-mixed boundary layer, about $1 \mathrm{~km}$ deep, with a sharp inversion of $\sim 8.5 \mathrm{~K}$ delineating the boundary layer from the free troposphere. The cloud layer is indicated by a layer of condensational warming (with potential temperature and vapor mixing ratio increasing and decreasing with height, respectively) ranging from 500 to $1050 \mathrm{~m}$ (AGL) where potential temperature $\theta$ increases with height and vapor mixing ratio $q_{v}$ decreases with height. From a simple thermodynamic perspective, these soundings would likely be classified as nearly well mixed, but we will demonstrate using large-eddy simulation that the boundary layer is decoupled into distinct cloud and subcloud layers.

The separate cloud and subcloud layers are apparent in the moisture field $\left(q_{v}\right)$ as well, although the subcloud moisture profiles are less well mixed than the temperature profiles. The mixing ratio profiles do not exhibit the large reduction in moisture across the inversion typically 
observed in marine stratocumulus (e.g., James 1959; Brost et al. 1982; Nicholls 1984). In fact, 2 of the 3 soundings contain notable spikes of $1-2 \mathrm{~g} \mathrm{~kg}^{-1}$ over a depth from 100 to $200 \mathrm{~m}$ above the inversion. Speculating, we attribute this feature to wetting of the humidity sensor as it passes through the cloud (Lorenc et al. 1996), though typically sensor wetting is accompanied by a spurious cooling of the temperature profile once the sonde passes through the cloud. Kim et al. (2005) show a number of soundings over the ACRF that exhibit similar increases in $q_{v}$ across the inversion but also accompany a natural transition to higher freetropospheric humidity, which suggests that the layer of high moisture content in our case is spurious. Subsidence is typically a stabilizing mechanism, acting to strengthen (make more negative) the moisture gradient across the inversion. In this case, the vertical moisture gradient in the free troposphere is quite small, so any subsidence present will enhance the moisture gradient only minimally. Except for the lowest 250-m layer, the $v$ momentum is constant with height, whereas $u$ exhibits about $13 \mathrm{~m} \mathrm{~s}^{-1}$ of shear over the 1-km-deep boundary layer.

Over the 3-h period during which the soundings were taken, the post-cold-frontal boundary layer cools and dries with time. From 0533 to 0743 UTC, the temperature inversion appears to sharpen considerably. There is no clear tendency of boundary layer deepening (or becoming more shallow), which is consistent with the upper cloud boundary as observed by cloud radar (Fig. 2 in MKS). The cloud thins with time, in this case manifested by ascent of cloud base. In a mixed layer framework, a boundary layer with constant moisture that cools results in a thicker cloud because of the decrease in equilibrium (saturation) mixing ratio. In this particular case, however, the drying overwhelms the cooling (Fig. 7 in MKS), ultimately resulting in the cloud thinning.

From the observed soundings in Fig. 2, we construct a simplified sounding to initialize the model. The thermodynamic profiles most closely match the 0743 UTC sounding, chosen because it represents a time when the cloud system was most steady. The idealized temperature sounding is characterized by a well-mixed boundary layer topped by an $8.5-\mathrm{K}$ temperature inversion and a stably stratified free troposphere. Boundary layer moisture is also assumed to be well mixed. Based on the reasoning outlined above that the observed 100-200-m moist layer above the inversion was spurious, we assume that the mixing ratio profile above the inversion decreases gradually with height at a rate indicated by the observations.

To specify the downwelling longwave radiative flux at the model upper boundary, we assume a water vapor path of $4.3 \mathrm{~kg} \mathrm{~m}^{-2}$, calculated from the observational soundings. This value results in a downwelling longwave flux at the model domain top consistent with that calculated from soundings using the more complicated delta-four-stream radiative transfer method of $\mathrm{Fu}$ and Liou $(1992,1993)$ over the full depth of the troposphere.

Surface fluxes were obtained from the eddy-correlation instrument located at the SGP site. The variability in both heat and moisture fluxes from the surface was remarkably small during the period of interest, so we imposed constant surface fluxes for the duration of the simulation. Surface sensible heat was assumed to be negligible $\left(0 \mathrm{~W} \mathrm{~m}^{-2}\right)$, and the latent heat flux was assumed to be $20 \mathrm{~W} \mathrm{~m}^{-2}$. The surface stress, obtained from momentum fluxes observed by the eddy-correlation instrument, was imposed as a constant value, $0.4 \mathrm{~m}^{2} \mathrm{~s}^{-2}$.

LES for marine stratocumulus is typically conducted in a Lagrangian framework, moving with the flow (e.g., Moeng et al. 1996; Stevens et al. 2005; Ackerman et al. 2009). In barotropic environments associated with marine stratocumulus, explicitly accounting for the horizontal advective tendencies is unnecessary. Our continental case, on the other hand, requires the advective forcings for two reasons. Since the LES is compared with observations at a fixed point (e.g., cloud radar, microwave radiometer), an Eulerian framework is necessary. Furthermore, a midlatitude synoptic cyclone is by definition baroclinic, with wind and advection terms that vary with height.

Horizontal advective tendencies of temperature, moisture, as well as the vertical velocity at the ACRF location, are estimated from the RUC model, denoted by " $C$ " in Fig. 3. The RUC horizontal temperature advection in Fig. 3 at 0600 and 0900 UTC indicates cold advection at low levels (below $600 \mathrm{~m}$ at 0900 UTC) transitioning to warm advection in the layer up to $2 \mathrm{~km}$. Although drying might be expected in a post-cold-frontal environment, the RUC values vary widely, ranging from $-1 \times 10^{7} \mathrm{~kg} \mathrm{~kg}^{-1} \mathrm{~s}^{-1}$ to an increase of $0.6 \times 10^{-7} \mathrm{~kg} \mathrm{~kg}^{-1} \mathrm{~s}^{-1}$. (These values correspond to synoptic-scale drying of $-0.36 \mathrm{~g} \mathrm{~kg}^{-1} \mathrm{~h}^{-1}$ and moistening of $0.22 \mathrm{~g} \mathrm{~kg}^{-1} \mathrm{~h}^{-1}$, respectively.) The synopticscale vertical velocity obtained from the RUC model is characterized by weak upward vertical motion whose intensity varies in time and space (Fig. 5 in MKS). The variability in both magnitude and sign of the vertical velocity differs from the predominant subsidence associated with marine stratocumulus. Because of the small magnitude of the vertical velocity, it was assumed to be zero for the control simulation.

\section{b. Experimental configuration for the sensitivity experiments}

Recognizing that this case of continental stratocumulus was associated with baroclinic environments characterized by strong time-dependent advective forcing and heterogeneous spatial structures, we formulated a suite of 

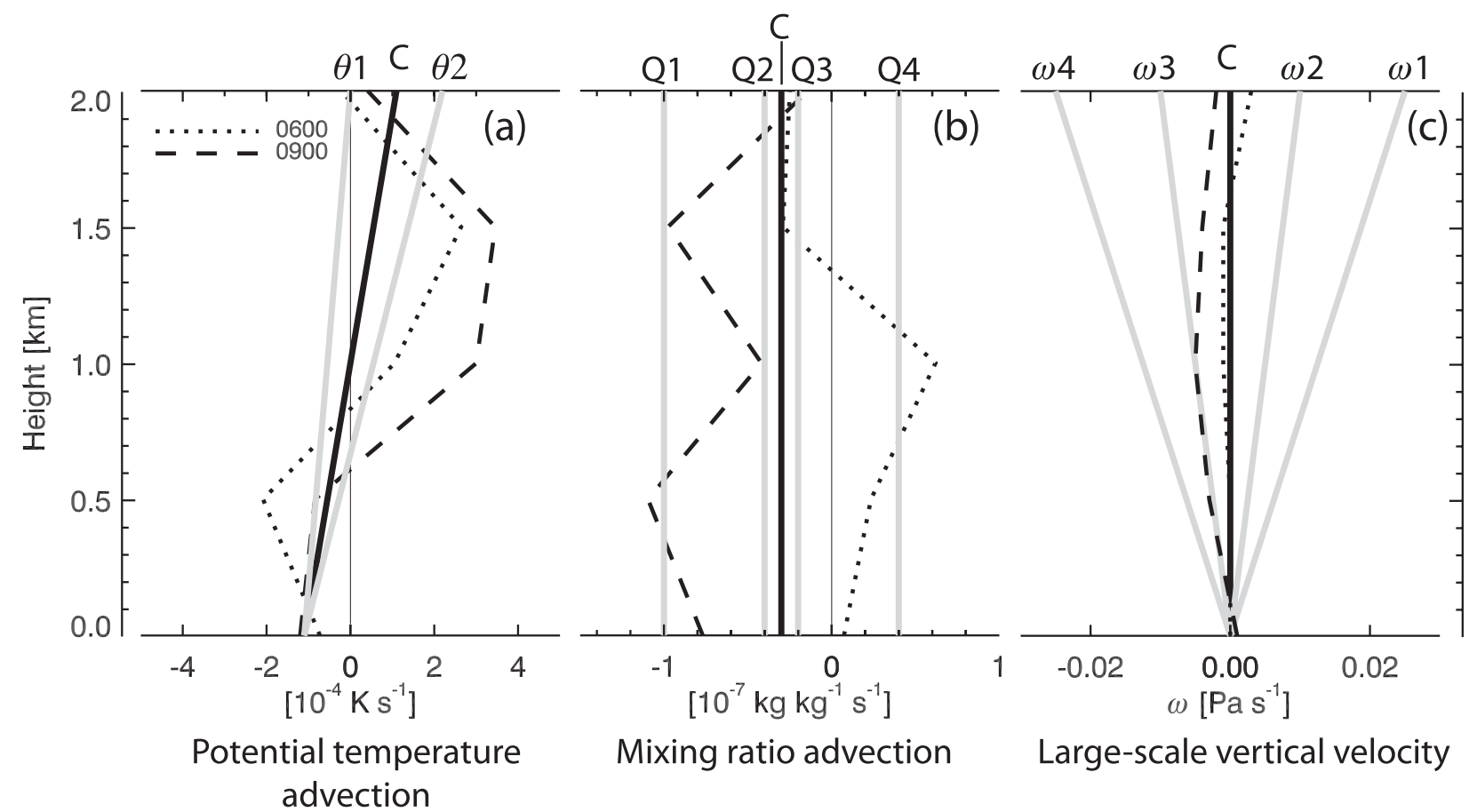

Mixing ratio advection

Large-scale vertical velocity

FIG. 3. Large-scale forcing obtained from the RUC analysis and applied to the simulations. (a) Potential temperature tendency; (b) mixing ratio tendency; (c) vertical velocity. Dotted and dashed lines represent the RUC profiles at 0600 and 0900 UTC, respectively. The dark solid line denoted " $\mathrm{C}$ " indicates the forcings applied to the control simulation. The gray lines denote forcing profiles corresponding to different sensitivity simulations described in the text and summarized in Table 1.

simulations to explore the sensitivity of continental boundary layer cloud systems to changes in forcing. The gray lines in Fig. 3 denote the forcings associated with the advective tendencies and vertical velocity for a number of sensitivity runs. All the simulations are summarized in Table 1.

Two sensitivity simulations were performed, each varying the horizontal temperature advection profile (Fig. 3a). In these simulations, the temperature advection at the surface remains at the same value as the control simulation $\left(-1.1 \times 10^{-4} \mathrm{~K} \mathrm{~s}^{-1}\right.$ or $\left.-0.40 \mathrm{~K} \mathrm{~h}^{-1}\right)$, whereas at $z=$ $2 \mathrm{~km}$ it is varied from $0.0 \mathrm{~K} \mathrm{~s}^{-1}$ to $2.2 \times 10^{-4} \mathrm{~K} \mathrm{~s}^{-1}$ $\left(0.79 \mathrm{~K} \mathrm{~h}^{-1}\right)$. All the profiles of temperature advection, including for the control simulation, affect not only the temperature but also the vertical stratification. The $\theta 2$ profile, for example, is the most stabilizing of the three.

Four simulations varying horizontal moisture advection were run. In these experiments (summarized in Fig. $3 \mathrm{~b}$ and Table 1) we imposed four different values of moisture advection, each constant in height and ranging from $-1.0 \times 10^{-7}$ to $0.4 \times 10^{-7} \mathrm{~kg} \mathrm{~kg}^{-1} \mathrm{~s}^{-1}$ (corresponding to synoptic-scale drying of $-0.36 \mathrm{~g} \mathrm{~kg}^{-1} \mathrm{~h}^{-1}$ and moistening of $0.14 \mathrm{~g} \mathrm{~kg}^{-1} \mathrm{~h}^{-1}$, respectively). Two sensitivity experiments were performed using different values for temperature advection.
Four profiles of vertical motion were imposed, each corresponding to constant values of synoptic-scale divergence. Although the RUC indicates that the magnitude of the vertical motion was small at these two particular times $\left(-0.005 \mathrm{~Pa} \mathrm{~s}^{-1}\right)$, Fig. 4b in Field and Wood (2007) suggests that larger values of vertical velocity can accompany stratocumulus (from 0.02 to $0.2 \mathrm{~Pa} \mathrm{~s}^{-1}$ at $z=2 \mathrm{~km}$, corresponding to divergence values from $10^{-6}$ to $10^{-5} \mathrm{~s}^{-1}$ ). The subsidence magnitudes chosen for the $\omega 1$ and $\omega 4$ simulations correspond to modest values of divergence of $\pm 1.25 \times 10^{-6} \mathrm{~s}^{-1}$.

Two suites of simulations varying surface fluxes were conducted. In the LE simulations, we imposed latent heat flux values of either 0 or $40 \mathrm{~W} \mathrm{~m}^{-2}$, and in the $H$ simulations sensible heat flux was assumed to be 10 or $20 \mathrm{~W} \mathrm{~m}^{-2}$.

\section{Control simulation}

Mean profiles for the control simulation (Fig. 4), calculated over two 1-h intervals, show the boundary layer deepening with time at a rate of $0.84 \mathrm{~cm} \mathrm{~s}^{-1}$ (the entrainment rate because the imposed subsidence is zero). The specific intervals of 3-4 h and 5-6 $\mathrm{h}$ were chosen for comparison with profiles from the W-band cloud radar (Figs. 6 and 7 in MKS). The potential temperature 
TABLE 1. Summary of LES simulation parameters for the control and sensitivity simulations. The simulation prefixes $\theta, Q, \omega($ at $z=$ $2 \mathrm{~km}), \mathrm{LE}$, and $H$ represent simulations in which temperature advection, moisture advection, synoptic-scale vertical velocity, surface latent heat flux, and surface sensible heat flux are varied from the control simulation, respectively. For visual clarity, each simulation in the table reflects only the quantity that was changed from the control simulation.

\begin{tabular}{|c|c|c|c|c|c|c|}
\hline & $\begin{array}{c}-\mathbf{V} \cdot \mathbf{\nabla} \theta \\
\left(10^{-4} \mathrm{~K} \mathrm{~s}^{-1}\right)\end{array}$ & $\begin{array}{c}-\mathbf{V} \cdot \nabla q_{v} \\
\left(10^{-7} \mathrm{~kg} \mathrm{~kg}^{-1} \mathrm{~s}^{-1}\right)\end{array}$ & $\begin{array}{c}\omega \\
\left(\mathrm{Pa} \mathrm{s}^{-1}\right)\end{array}$ & $\begin{array}{c}\mathrm{LE} \\
\left(\mathrm{W} \mathrm{m}^{-2}\right)\end{array}$ & $\begin{array}{c}H \\
\left(\mathrm{~W} \mathrm{~m}^{-2}\right)\end{array}$ & $\left(\mathrm{m}^{2} \mathrm{~s}^{-2}\right)$ \\
\hline Control & -1.1 to 1.1 & -0.3 & 0.0 & 20 & 0.0 & 0.4 \\
\hline$\theta 1$ & -1.1 to 0.0 & & & & & \\
\hline$\theta 2$ & -1.1 to 2.2 & & & & & \\
\hline$Q 1$ & & -1.0 & & & & \\
\hline$Q^{2}$ & & -0.4 & & & & \\
\hline$Q 3$ & & -0.2 & & & & \\
\hline$Q 4$ & & 0.4 & & & & \\
\hline$\omega 1$ & & & 0.0025 & & & \\
\hline$\omega 2$ & & & 0.001 & & & \\
\hline$\omega 3$ & & & -0.001 & & & \\
\hline$\omega 4$ & & & -0.0025 & & & \\
\hline LE1 & & & & 0.0 & & \\
\hline LE2 & & & & 40 & & \\
\hline$H 1$ & & & & & 10 & \\
\hline$H 2$ & & & & & 20 & \\
\hline
\end{tabular}

profile exhibits a slight increase near $650 \mathrm{~m}$, which is often present when the cloud layer decouples from the subcloud layer. In the control simulation, the stratification of the liquid water potential temperature $\theta_{l}$ profile is also consistent with the profile of potential temperature advection (warm advection over cold advection). Despite the fact that our initial moisture profile was constant with height (see the well-mixed boundary layer moisture profile in Fig. 2), the moisture profile evolves to be slightly stratified, similar to the observations. The profile dries with time, an effect arising directly from the synoptic-scale advective tendency of moisture, because drying via entrainment is weak. Peak liquid water content decreases with time, as does cloud thickness (although it is difficult to determine this visually from the $q_{l}$ profile in Fig. 4). The $u$ and $v$ wind profiles exhibit a similar decoupled behavior suggested by the temperature profile, with momentum well mixed in the cloud layer and then stratified below.

Mean profiles of higher-order moments and turbulent fluxes from the LES control simulation provide more insight into the evolution of the flow (Fig. 5). The pronounced minimum in the variance $\left.\overline{\left(w^{\prime} w^{\prime}\right.}\right)$ profile between 600 and $700 \mathrm{~m}$ is consistent with the decoupling of the cloud and subcloud layers, suspected from the liquid water potential temperature profile in Fig. 4. The turbulence
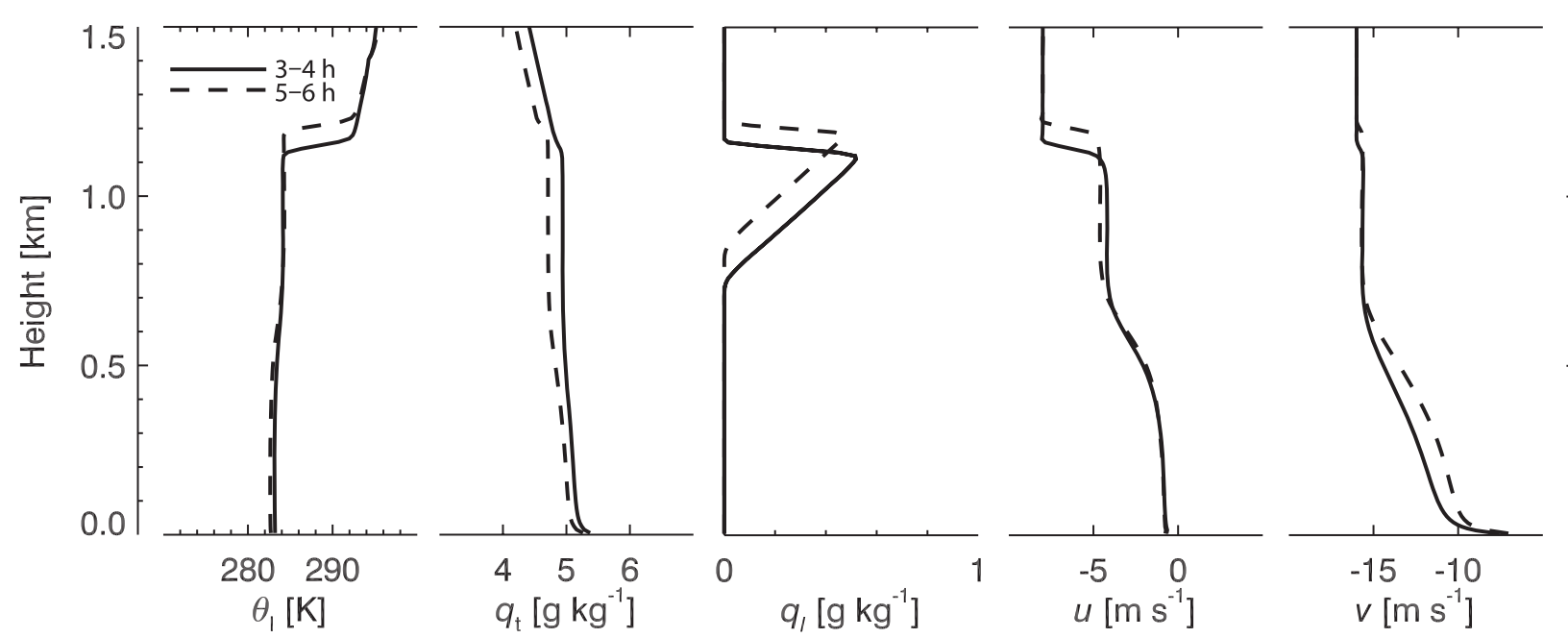

FIG. 4. Mean profiles of liquid water potential temperature $\left(\theta_{l}\right)$, total water $\left(q_{t}\right)$, liquid water mixing ratio $\left(q_{l}\right), u$, and $v$, taken over the indicated intervals. 

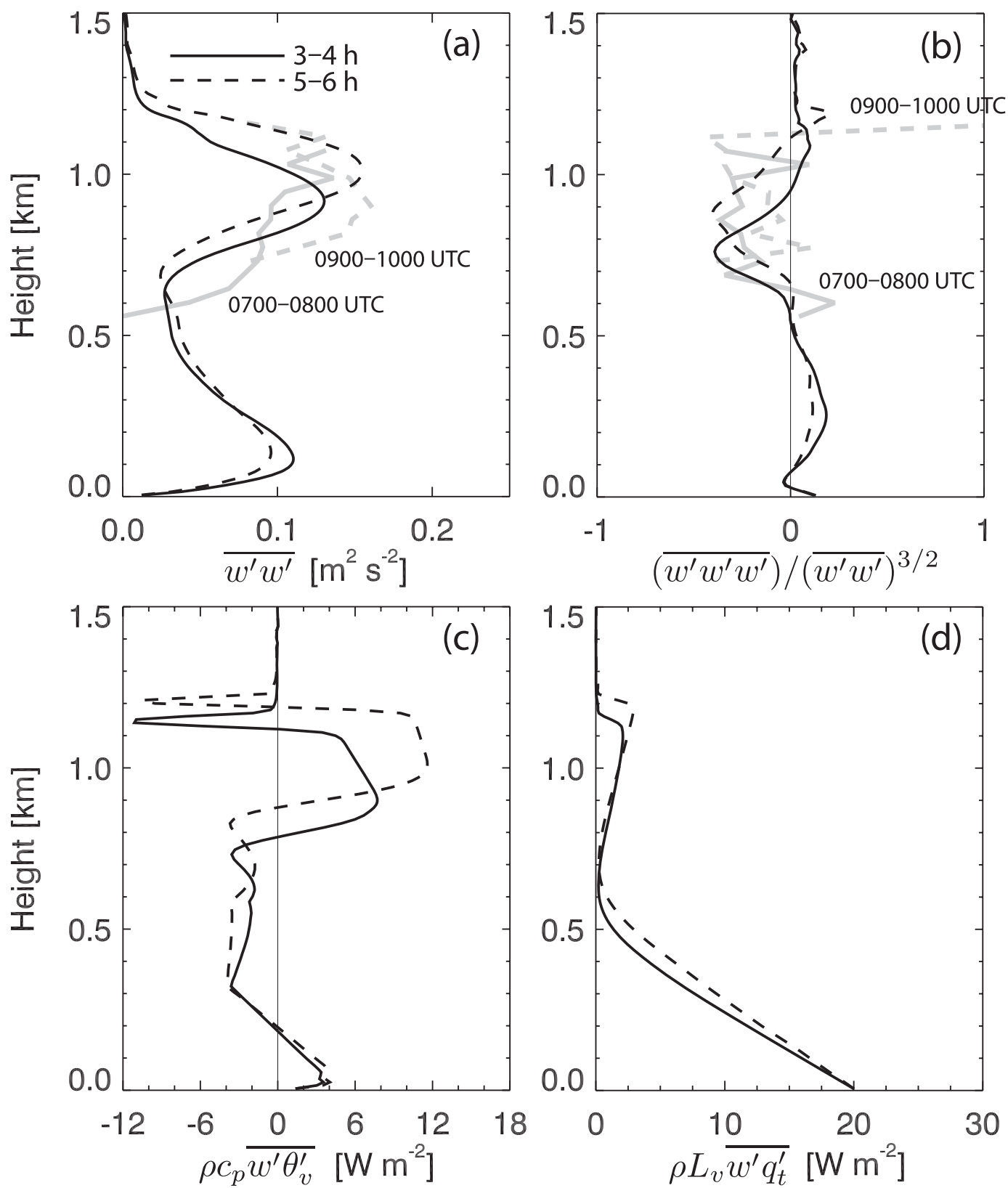

FIG. 5. Mean profiles of (a) vertical velocity variance $\left(\overline{w^{\prime} w^{\prime}}\right)$, (b) skewness $\left[\left(\overline{w^{\prime} w^{\prime} w^{\prime}}\right) /\left(\overline{w^{\prime} w^{\prime}}\right)^{3 / 2}\right]$, (c) buoyancy flux $\left(\rho c_{p} \overline{w^{\prime} \theta_{v}^{\prime}}\right)$, and (d) total water flux $\left(\rho L_{v} \overline{w^{\prime} q_{t}^{\prime}}\right)$ for the control simulation. The gray lines in (a) and (b) represent variance and skewness at the indicated times, calculated from the ARM W-band cloud radar (WACR). See MKS for details about the radar data processing.

associated with the upper peak in $\overline{w^{\prime} w^{\prime}}$ from $900 \mathrm{~m}$ to $1 \mathrm{~km}$ in Fig. 5a is most likely driven by cloud-top cooling, whereas the weaker, lower maximum at $100-150 \mathrm{~m}$ is probably driven by shear (since the sensible heat flux $H$ in the control case is zero) and a weak contribution to buoyancy from the surface moisture flux. A TKE budget presented in section 5 will confirm that turbulence in the subcloud layer is predominantly driven by shear.
The skewness $\left(\overline{w^{\prime} w^{\prime} w^{\prime}}\right) /\left(\overline{w^{\prime} w^{\prime}}\right)^{3 / 2}$ profiles in Fig. 5b also imply two distinct dynamics: a cloud layer, driven in a top-down fashion by longwave radiative cooling (as in Moyer and Young 1991), and a subcloud layer driven by surface-based mechanisms (some combination of shear and buoyancy). The simulation furthermore demonstrates the transition from negative values of skewness at cloud base to positive values at the top of the cloud, 
a behavior attributed by Moeng and Rotunno (1990) to the combination of a small number of surface-based updrafts able to penetrate vertically to the inversion along with weak downdrafts covering a larger area. This transition was not present in the large-eddy observations of MKS, although it was observed for a different case by Kollias and Albrecht (2000). The radar sampling strategy of Kollias and Albrecht was optimized for specifically characterizing low clouds, and we suspect their finer vertical gate spacing of $28 \mathrm{~m}$ (relative to $42.9 \mathrm{~m}$ in MKS) played a role in capturing this subtle boundary layer structure.

To evaluate the LES results, in Fig. 5 we overlaid vertical velocity variance and skewness profiles from the 95-GHz W-band ARM Cloud Radar (WACR) (MKS). Because of the lack of scatterers in the subcloud layer, the radar gives data only for cloudy regions, and variance and skewness is not available below cloud base (750 and $850 \mathrm{~m}$ for the two periods, respectively). Both LES and WACR profiles are calculated over hour-long periods. Relative to the WACR, the LES captures reasonably well the evolution of the turbulent intensities in this case (Fig. 5a). For the two analysis periods, the maximum variance from the WACR is 0.14 and $0.16 \mathrm{~m}^{2} \mathrm{~s}^{-2}$, compared with 0.13 and $0.15 \mathrm{~m}^{2} \mathrm{~s}^{-2}$ from the LES. The maximum in the LES profile corresponding to the later period is noticeably deeper $(\sim 120 \mathrm{~m})$ than for the WACR profile, which can be attributed to the boundary layer in the model deepening over this period at a greater rate than the observed boundary layer deepens. This discrepancy may be the result of the LES overestimating entrainment, an underestimate in our choice for subsidence, or our choice of averaging periods for the WACR data. The fact that the model represents the turbulent intensity well suggests that the entrainment rate is not the culprit for the mismatch in boundary layer depth between observations and model. We note that, although the cloud fraction of the stratocumulus as a whole is $100 \%$, the cloud fraction at cloud top and cloud base may be considerably less. The difference in how the turbulent statistics are calculated between LES (over the entire boundary layer) and WACR (over cloudy regions only) may explain some of the discrepancy between LES and WACR statistics near the cloud base and cloud top. The time series of radar data for this case (Fig. 6 in MKS) indicates that the boundary layer depth does not uniformly deepen over the 0600-1000 UTC period but rather deepens over some periods and becomes more shallow over others, suggesting that more accurately representing the synoptic-scale vertical motion in the model would be appropriate. The general shape of the variance profiles are captured well, in particular the decrease in variance near cloud base that is associated with decoupling.

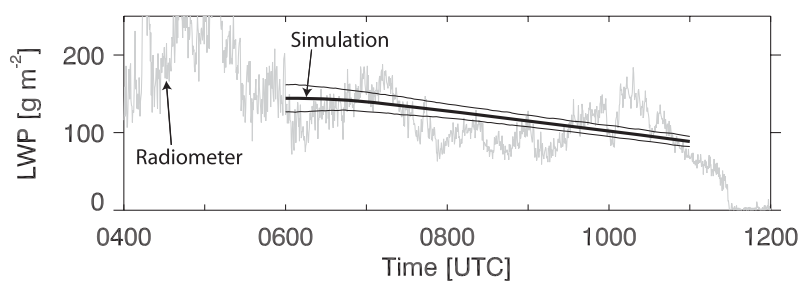

FIG. 6. Simulated LWP overlaid on the LWP obtained from the microwave radiometer. The dark line corresponds to the mean; the two outer lines correspond to the $\pm 2 \sigma$ interval.

Skewness, being a higher-order statistic, is noisier, but Fig. $5 b$ indicates that the LES captures the negative skewness in the cloud layer (from 550 to $1150 \mathrm{~m}$ ). As mentioned above, the regions of positive skewness in profiles near cloud top are not captured by the WACR, though one data point at $z=1150 \mathrm{~m}$ in the 0900 1000 UTC profile hints at the transition to positive skewness in the upper portion of the cloud.

The deep region of negative buoyancy flux (200-800 m) over much of the subcloud layer (Fig. 5c) indicates that a substantial portion of the boundary layer circulation is thermodynamically indirect (cold updrafts, warm downdrafts). Whereas a negative buoyancy flux just below cloud base is one symptom of decoupling (Stevens 2000), it is less common to see such a pronounced deep layer of negative buoyancy flux. This layer of negative buoyancy is consistent with the bimodal $\overline{w^{\prime} w^{\prime}}$ profile, which best indicates that the cloud and subcloud layers are largely two distinct circulations.

The absence of precipitation greatly simplifies the total water flux (Fig. 5d). These profiles imply a moistening due to turbulent transport from the surface up to 650 $700 \mathrm{~m}$ and a slight decrease with time from $700 \mathrm{~m}$ up to the inversion. The advective drying (Fig. 3b), however, is greater than this moistening, resulting in a net subcloud (and boundary layer) drying.

Figure 6 compares $5 \mathrm{~h}$ of liquid water path (LWP) calculated from the model to LWP obtained via retrieval from the microwave radiometer described in MKS. The simulation captures the long-term decrease (trend) in LWP with the $\pm 2 \sigma$ envelope roughly representing the short-term variability. The simulation does not capture the variability at the intermediate scales (from 5 min to $4 \mathrm{~h}$ ). These scales constitute mesoscale aspects of the flow that the small model domain $\left(4.4 \times 4.4 \mathrm{~km}^{2}\right)$ is unable to resolve.

\section{Sensitivity experiments}

Figures 7 and 8 summarize the sensitivity simulations specified in Table 1. As we will discuss, for the most part the simulations respond predictably to changes in model 

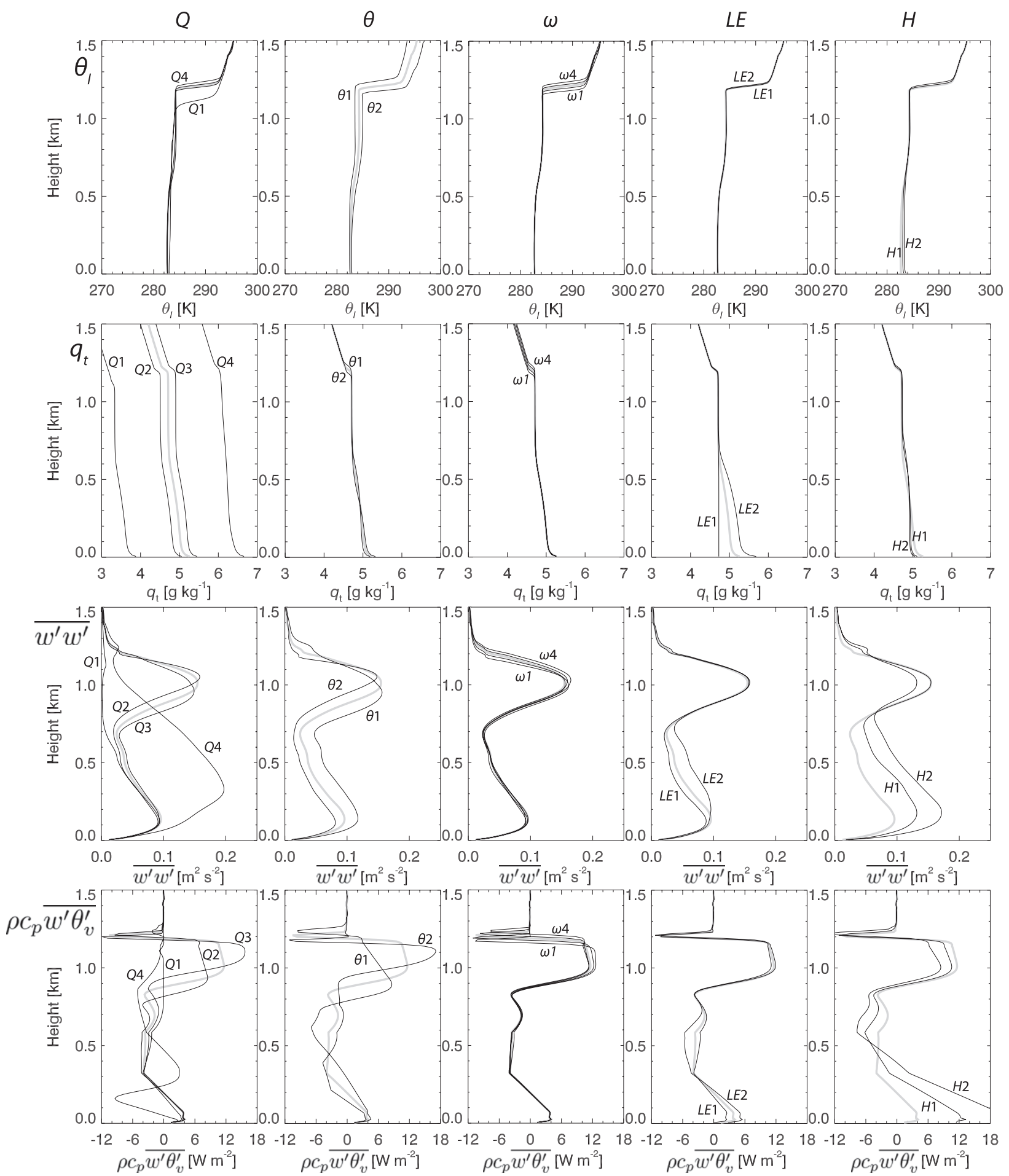

FIG. 7. Ensemble of all simulations, categorized by sensitivity simulation type. Each column represents a suite of simulations varying the horizontal moisture advection, horizontal potential temperature advection, synoptic-scale vertical velocity, surface latent heat flux, and surface sensible heat flux. The thick gray line signifies the control simulation. All profiles are calculated over the last simulation hour (5-6 h). Rows correspond to liquid water potential temperature, total water, vertical velocity variance, and buoyancy flux. Where possible, profiles corresponding to particular simulations are noted. 


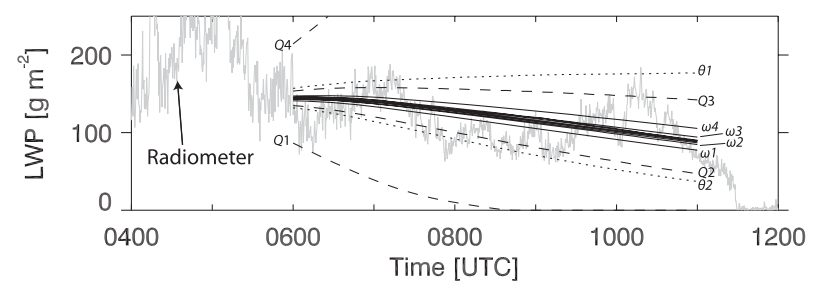

FIG. 8. As in Fig. 6 but for all 15 simulations. Because their time series differ so little from the control simulation, LE1, LE2, $H 1$, and $H 2$ are not explicitly labeled.

forcing. The results support the conclusions of Stevens et al. (1999) and Stevens and Feingold (2009), who argue that specific mechanisms (e.g., the nonlinear relationship between entrainment and boundary layer energetics) serve to reduce the sensitivity of the simulation to parameter changes. When applied to microphysical parameters, Stevens and Feingold refer to this reduced sensitivity as aerosol-cloud-precipitation mechanisms "buffering" the boundary layer cloud properties. Applied to our ensemble, this buffering process implies a reduced sensitivity to changes in forcing.

We suspect our simulations generally respond predictably to changes in thermodynamic forcing (potential temperature and moisture advection) because the buoyancy reversal process does not appear to be active. As originally conceived by Siems et al. (1990), buoyancy reversal applies to a two-layer fluid in which some mixtures of air from the two layers are less buoyant than either individual fluid. Buoyancy reversal is the mechanism underlying cloud-top entrainment instability (CTEI), a proposed positive feedback between entrainment and evaporative cooling associated with mixtures of cloudy and entrained free-tropospheric air. CTEI was originally suggested by Lilly (1968) and more thoroughly developed by Randall (1980) and Deardorff (1980a) as a mechanism that can ultimately lead to the decay of a stratocumulus cloud layer. Buoyancy reversal is a necessary but not sufficient condition for CTEI (e.g., Yamaguchi and Randall 2008). Although Siems et al. (1990) and Gerber et al. (2005) point out that the entrainment instability idea is not supported by observational data, the buoyancy reversal criterion has physical meaning and serves as a useful tool for stratifying buoyancy-driven cloud-topped boundary layers (Moeng 2000).

Taken from Stevens et al. (2003) and framed in the thermodynamic variables of the LES, the condition for buoyancy reversal is

$$
\kappa \equiv 1+\frac{c_{p} \Delta \theta_{l}}{L \Delta q_{t}}>\kappa_{*}
$$

where $\Delta \theta_{l}$ and $\Delta q_{t}$ are the temperature and moisture jumps, respectively, across the inversion. The parameter $\kappa$ represents the relative contributions of evaporative cooling and warming (resulting from entrainment) for mixtures of cloudy and free-tropospheric air. The threshold $\kappa_{*}$ depends on cloud-top temperature and pressure, and previous studies (Moeng 2000; Stevens et al. 2003) employed the value developed by Randall (1980) $\left(\kappa_{*} \approx\right.$ 0.23 ) in his formulation of CTEI theory. For our continental stratocumulus case, cloud-top temperature and pressure were $275 \mathrm{~K}$ and $870 \mathrm{mb}$, resulting in $\kappa_{*} \approx$ 0.18 .

We estimate the liquid water potential temperature jump across the inversion in our case to be $\Delta \theta_{l} \approx 8.5 \mathrm{~K}$. Assuming from our sounding that a moisture jump of zero $\left(\Delta q_{t} \approx 0\right)$ leads to (1) being mathematically undefined. If, just for argument's sake, we assume a moisture jump of $-1.0 \mathrm{~g} \mathrm{~kg}^{-1}$, the buoyancy reversal parameter $\kappa$ becomes -2.4 , which still lies well within the stable regime. In fact, given $\Delta \theta_{l} \approx 8.5 \mathrm{~K}, \Delta q_{t}$ would need to be $-4.2 \mathrm{~g} \mathrm{~kg}^{-1}$ for the buoyancy reversal condition in (1) to be satisfied. Therefore, the buoyancy reversal mechanism (and CTEI) does not apply to our case.

Figure 7 summarizes mean profiles over the last simulation hour for the sensitivity experiments. Although we did not perform a rigorous quantitative sensitivity analysis in the manner of Chlond and Wolkau (2000) and Chlond et al. (2004), the comparison in Fig. 7 nevertheless suggests to which parameters the simulations respond most strongly.

The moisture series $Q$ exhibits only modest spread (Fig. 7), except for the moisture advection bookend cases of $Q 1$ and $Q 4$, in which the final boundary layer moisture is either dry or moist. The liquid water path in Fig. 8 exhibits similar variation between the $Q$ simulations, with $Q 1$ (characterized by strong dry advection) becoming cloud free by 0800 UTC. Once the cloud dissipates, cloud-top radiative cooling is no longer active, and cloud-layer turbulence (as indicated in Fig. 7 by the near-zero profiles of $\overline{w^{\prime} w^{\prime}}$ and buoyancy flux $\overline{w^{\prime} \theta_{v}^{\prime}}$ from $750 \mathrm{~m}$ upward) is greatly reduced. The shallower boundary layer depth, visible in the profile of $\theta_{l}$ that is nearly $125 \mathrm{~m}$ less than for the control simulation, is consistent with the lack of turbulence in the upper boundary layer and the resulting lack of entrainment at the inversion.

Simulation $Q 4$ behaves very differently from the other runs in the $Q$ series. In $Q 4$, the boundary layer moistens so much that liquid water content at cloud top becomes $1.2 \mathrm{~g} \mathrm{~kg}^{-1}$, and the cloud extends to within $200 \mathrm{~m}$ of the ground ( $q_{l}$ profile not shown). Why does $Q 4$ not contain the typical midcloud maximum in $\overline{w^{\prime} w^{\prime}}$, and why is the buoyancy flux negative over much of the cloud layer (from 550 to $1200 \mathrm{~m}$ )? The answer seems to lie in the high moisture values in the boundary layer and free 
troposphere and the large liquid water content at cloud top. For typical cloud-topped boundary layers, the cloud top intrudes only slightly above the base of the inversion. In such a case, radiative cooling acts on parcels at the top of the boundary layer, with most of the cooling taking place below the inversion. The cooling generates negative buoyancy, which in turn drives the boundary layer turbulence that indirectly results in the entrainment of free-tropospheric air. In $Q 4$, evidently, cloudy air and the radiative cooling extend farther upward into the inversion. When displaced upward, relative to the control simulation, the radiative cooling acts directly to cool the inversion rather than indirectly by driving cloudlayer turbulence. The different partitioning, relative to the control simulation, of the radiative cooling between cloud layer and inversion suggests why turbulent intensity and buoyancy flux in the upper boundary layer are small in $Q 4$. Without buoyant generation of turbulence in the upper cloud layer that homogenizes the momentum profiles, we speculate that the $\overline{w^{\prime} w^{\prime}}$ peak of $0.2 \mathrm{~m}^{2} \mathrm{~s}^{-2}$ at $325 \mathrm{~m}$ arises from the shear-generation mechanism acting over the full depth of the boundary layer. Although the simulation appears to be acting in a physically consistent manner, it is an open question whether this behavior of thicker cloud being associated with weaker turbulent intensity is present in nature.

Relative to the control simulation, $\theta 1$ is less stabilizing, while $\theta 2$ is more stabilizing. The two sensitivity runs behave predictably, with the final $\theta_{l}$ profile in $\theta 2$ the more stable of the two, ultimately resulting in a shallower $(\sim 70 \mathrm{~m})$ boundary layer, thinner cloud (see the LWP in Fig. 8), and a reduced turbulent intensity over most of the boundary layer.

In the $\omega$ series, the simulation with the greatest subsidence $(\omega 1)$ results in the shallowest boundary layer, whereas the most positive vertical motion results in the deepest boundary layer (with the difference in boundary layer depth between $\omega 4$ and $\omega 1$ being approximately $65 \mathrm{~m}$ ). Turbulent intensity, buoyancy flux, and thermodynamic structure are largely similar in the $\omega$ simulations, indicating that for this particular case, synoptic-scale vertical motion has little effect on the turbulent boundary layer processes.

The LE sensitivity experiments most noticeably affect the subcloud layer. Simulation LE2 noticeably moistens this layer, with a maximum $q_{t}$ of $5.7 \mathrm{~g} \mathrm{~kg}^{-1}$ at the surface, and the greater moisture enhances the buoyancy of surface-based updrafts. When the surface moisture flux is zero (LE1), the $q_{t}$ profile is constant with height and lacks the telltale increase within few tens of meters above the surface. Although the difference in latent heat flux between the three simulations is $40 \mathrm{~W} \mathrm{~m}^{-2}$, the effect on cloud-layer turbulence is minimal because only a small fraction the latent heat flux is realized as condensation in the cloud.

Sensible heat flux directly drives boundary layer turbulence, which explains why $H 1$ and $H 2$ produce stronger turbulent intensities, but the ultimate effect on entrainment and boundary layer depth is rather subtle ( $H 2$ being $\sim 20 \mathrm{~m}$ deeper than the control simulation).

The suite of sensitivity simulations indicates that our continental boundary layer case is most acutely sensitive to potential temperature and moisture advection. These advective processes, particularly moisture advection, can fundamentally change the nature of the boundary layer circulation. On the other hand, synoptic-scale vertical motion tends to affect only the boundary layer depth, whereas latent heat flux predominantly influences the subcloud moisture and turbulence. Varying the sensible heat flux $H$ most directly influences subcloud-layer turbulence, although $H$ at night is most frequently negligible.

\section{Mixed layer scalings}

The simulation ensemble naturally lends itself to assessing whether scalings for entrainment rate (or flux) lend themselves to this particular case. VanZanten et al. (1999) summarized the work of Tennekes (1973) and Turner (1973), who demonstrated that in a mixed layer framework (zeroth-order model), entrainment rate $w_{e}$ scales with the convective velocity and inverse Richardson number $\mathrm{Ri}^{-1}$ :

$$
w_{e}=A w_{*} \mathrm{Ri}^{-1},
$$

where $A$ is a nondimensional entrainment efficiency taken to be the fraction of the integrated buoyancy flux that is applied to entrainment.

The Richardson number Ri is defined by

$$
\mathrm{Ri} \equiv \frac{\left(g / \theta_{0}\right) \Delta \theta_{v} z_{i}}{w_{*}^{2}},
$$

where $\Delta \theta_{v}$ is taken as the difference in virtual potential temperature over the inversion, which is at height $z_{i}$. The convective velocity scale is defined as usual as

$$
w_{*}^{3}=2.5 \int_{0}^{z_{i}} \frac{g}{\theta_{0}} \overline{w^{\prime} \theta_{v}^{\prime}} d z .
$$

We present some of these scalings in Fig. 9. Although most of the cloud LWP values are clustered near $100 \mathrm{~g} \mathrm{~m}^{-2}$, the entrainment rate is only weakly correlated with LWP (Fig. 9a). This broad behavior seems plausible, given that for optically thick clouds larger LWP will 

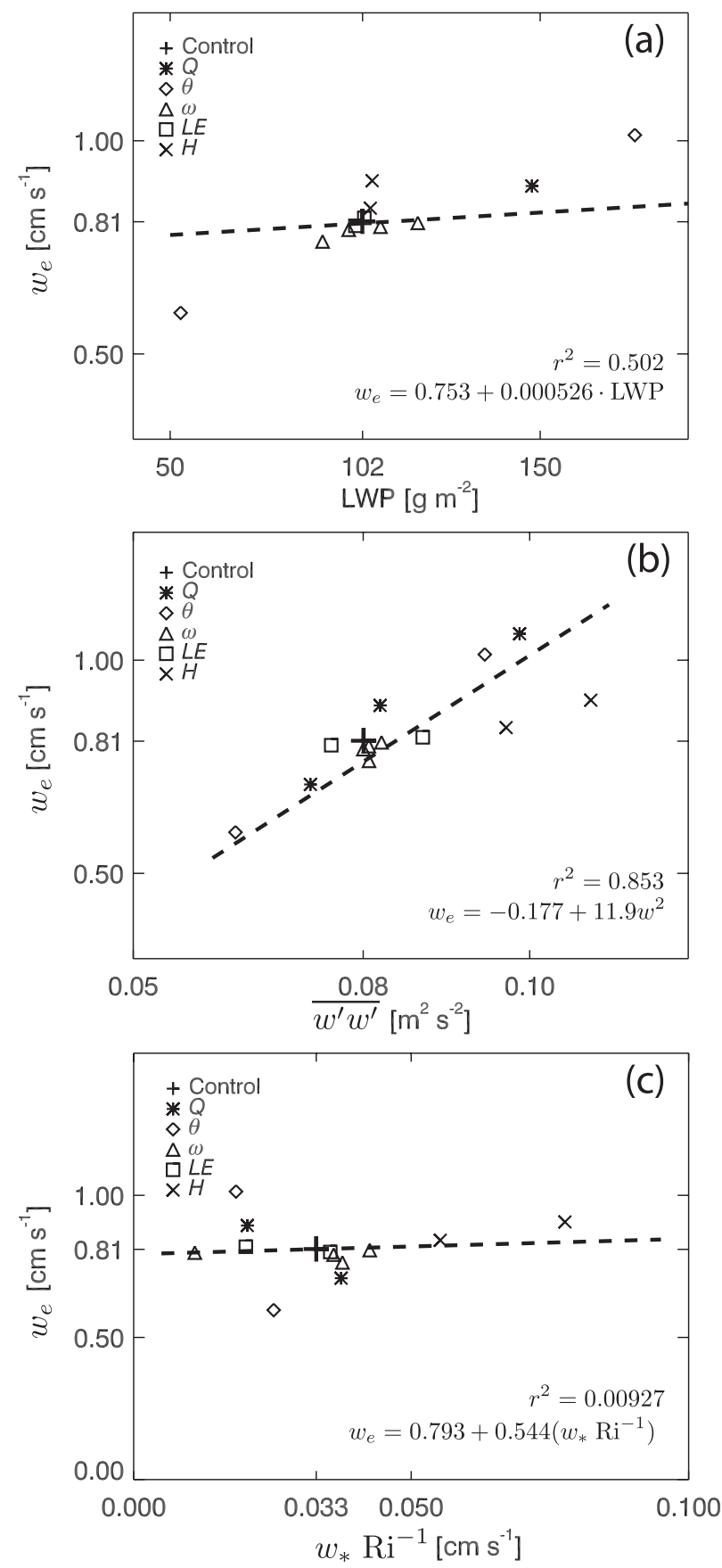

FIG. 9. Mixed layer scalings. Entrainment is plotted as a function of (a) liquid water path, (b) boundary layer averaged vertical velocity variance, and (c) convective velocity scaled by the inverse Richardson number. Dashed lines represent best fits calculated via linear regression. The best-fit parameters and the explained variance are listed on each panel. Note that the $Q 1$ simulation is omitted from the regression in (a) since LWP is zero. In (c) $w_{*} \mathrm{Ri}^{-1}$ is undefined for the $Q 1$ and $Q 4$ simulations, so they are omitted from the best-fit calculation. increase the radiative flux divergence at cloud top only negligibly. This weak correlation between entrainment rate and LWP is consistent with the results from the intercomparison of one-dimensional boundary layer models discussed in Zhu et al. (2005), who found that models with similar entrainment rates could have a wide variety of LWP values.

Figure $9 \mathrm{~b}$ indicates a clear relationship between boundary layer vertical velocity variance, averaged over the depth of the boundary layer and the last two hours of the simulation, and entrainment rate. Lewellen et al. (1996) found a similar relationship, though they scaled the square root of the vertical velocity variance by the Richardson number. For the sensitivity experiments, parameters that lead to larger values of $\overline{w^{\prime} w^{\prime}}$ are larger moisture advection, advection of a less stable temperature profile, synoptic-scale upward vertical velocity, and larger fluxes of heat and moisture. Of the individual cases, the simulations where surface latent (LE) and sensible $(H)$ heat fluxes are varied seem to affect entrainment rate very little. The reason for this insensitivity is almost certainly because the flow is decoupled, whereby these increases in surface fluxes are not communicated in the vertical to the upper layer. The larger fluxes do, however, increase the turbulent intensity for the lower (subcloud) layer.

The classical scaling in (2) fits the LES results poorly (Fig. 9c). Given the similarity between the simulations (Fig. 7), this result is rather surprising and suggests that $w_{*}$ is not an appropriate velocity scale in this case, either because the circulation is decoupled or because of the possibility that shear production plays a role in generating boundary layer turbulence. We discuss the role of shear production in section 6 .

Why is the scaling relationship between $w_{e}$ and mean variance good (Fig. 9b), yet the classical mixed layer scaling in Fig. 9c is much worse? The model boundary layer is clearly behaving according to conventional wisdom: stronger turbulence leads to greater entrainment rates. Our speculation concerning the poor performance of the mixed layer scalings is centered on Fig. 10 and the fact that in these simulations the convective velocity scale $w_{*}$ is a very poor proxy for turbulent intensity. One possible reason lies in the highly decoupled nature of the flow, as evinced by distinct subcloud and cloud-layer circulations visible in the vertical velocity variance and buoyancy flux profiles in Figs. 5 and 7. This case clearly violates the assumption of mixed layer theory that the boundary layer be well mixed. In this case, much of the circulation is thermodynamically indirect, in contrast to typical buoyancy-driven boundary layers that convert much of the potential energy into kinetic. We attempted other closures for convective velocity scale-for example, 


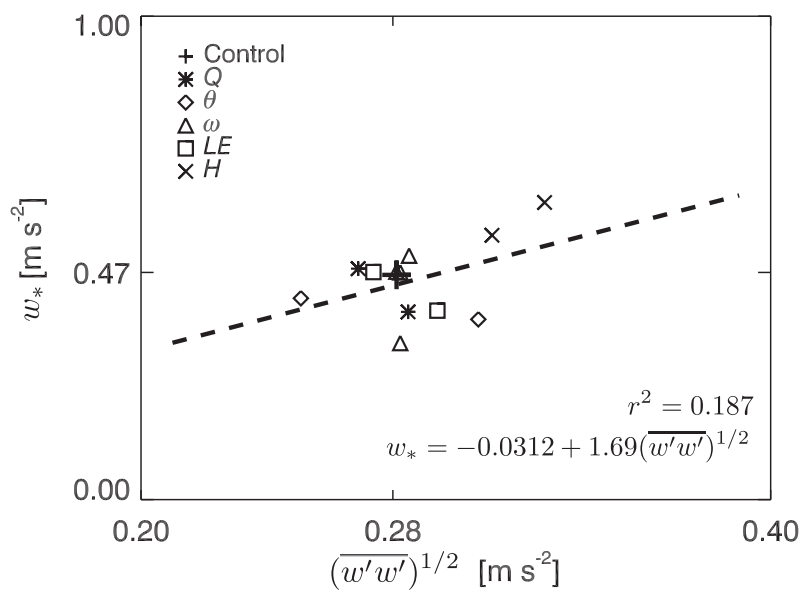

FIG. 10. Relationship between the square root of the vertical velocity variance and the convective velocity scale.

the unorthodox approach of calculating the buoyancy flux over the cloudy layer only or employing only regions of positive buoyancy flux (in the upper layer) associated with the thermally direct component of the flow. Unfortunately, none of our attempts based on $w_{*}$ alone resulted in a satisfactory scaling for $w_{e}$.

Although using the scaling in (2) directly for clouds is commonplace, other formulations have attempted to account for cloud-top longwave cooling by including in the scaling a portion of the radiative flux divergence occurring in the inversion [see the excellent discussions by Lock (1998) and Lock and MacVean (1999)]. In the classical Lilly (1968) treatment, all of the radiative flux was incorporated into the entrainment, which symbolized that the radiative flux directly affected the inversion temperature structure. Use of (2) for cloudy conditions, on the other hand, assumes that the radiative flux contributes totally to driving boundary layer turbulence and thus only influences the entrainment rate indirectly. Deardorff (1976) walked the middle ground and assumed more generally that some portion of the flux divergence applies to directly affecting the inversion:

$$
w_{e}=A w_{*} \mathrm{Ri}^{-1}+\beta \alpha \frac{\Delta F}{\Delta \theta_{v}},
$$

where $\alpha$ represents the fraction of the cloud-top radiative divergence occurring across the inversion, which Deardorff took to be 0.5 , and $\beta \approx 0.5$ is a weakly statedependent thermodynamic parameter. The two-term scaling requires that a choice be made for the entrainment efficiency $A$. We follow Caldwell and Bretherton (2009) and assume $A=1.1$. Note that for dimensional consistency the radiative flux difference $\Delta F$ is in units of temperature $\left(\mathrm{K} \mathrm{m}^{-1} \mathrm{~s}^{-1}\right)$. The use of (5), whereby

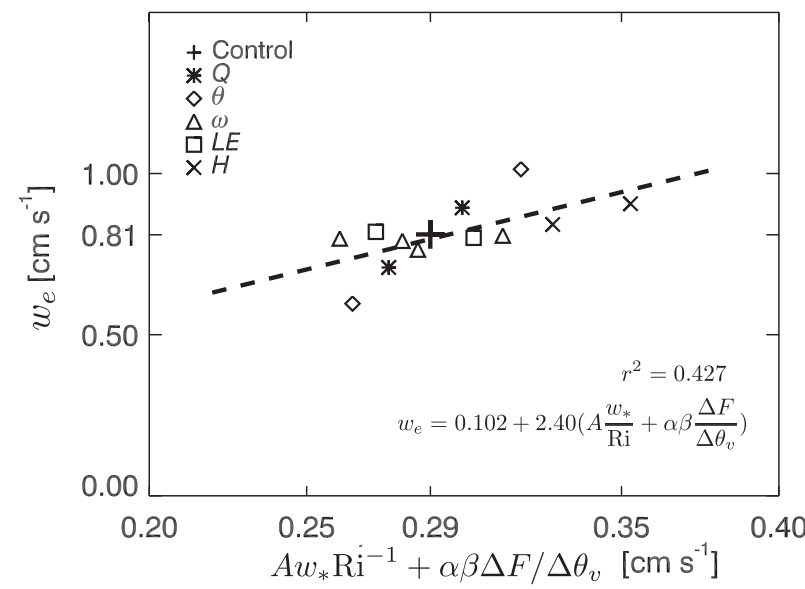

FIG. 11. Mixed layer scaling for entrainment rate based on a combination of the convective velocity scaled by the inverse Richardson number and a contribution of the radiative flux divergence.

a portion of the radiative flux was explicitly included in the entrainment formulation, improves noticeably the poor scaling based on $w_{*}$ alone (Fig. 11).

\section{TKE budget}

We calculated a TKE budget on the control simulation in order to explore the different mechanisms responsible for driving cloud- and subcloud-layer dynamics. The mean TKE profile in Fig. 12a is fairly typical for a turbulent boundary layer, with peaks in the upper cloud and near the surface. The buoyancy term is positive in the cloud (Fig. 12b), resulting from cloud-top radiative cooling, but is negative and suppresses TKE generation in the subcloud layer from 175 to $825 \mathrm{~m}$. While negative buoyancy flux is frequently present near cloud base, such a deep layer is uncommon. The transport term vertically redistributes TKE and is largely out of phase with the TKE itself (Fig. 12b). Over the subcloud layer, TKE transport counteracts loss from buoyancy.

The most surprising result from the TKE budget is the significant contribution of shear generation acting over the entire depth of the subcloud layer. This finding is consistent with the results of Zhu et al. (2001), who emphasized the importance of wind shear in the formation of nocturnal continental stratocumulus cloud systems. The role of the shear-generated turbulence might have been astutely guessed, given the shear in the wind profiles (both the LES in Fig. 4 and the original soundings in Fig. 2). Our strong suspicion is that the boundary layer scalings, formulated for buoyancy-driven boundary layer dynamics, perform poorly when shear is a significant component in the TKE budget. This result agrees with Tjernström and 


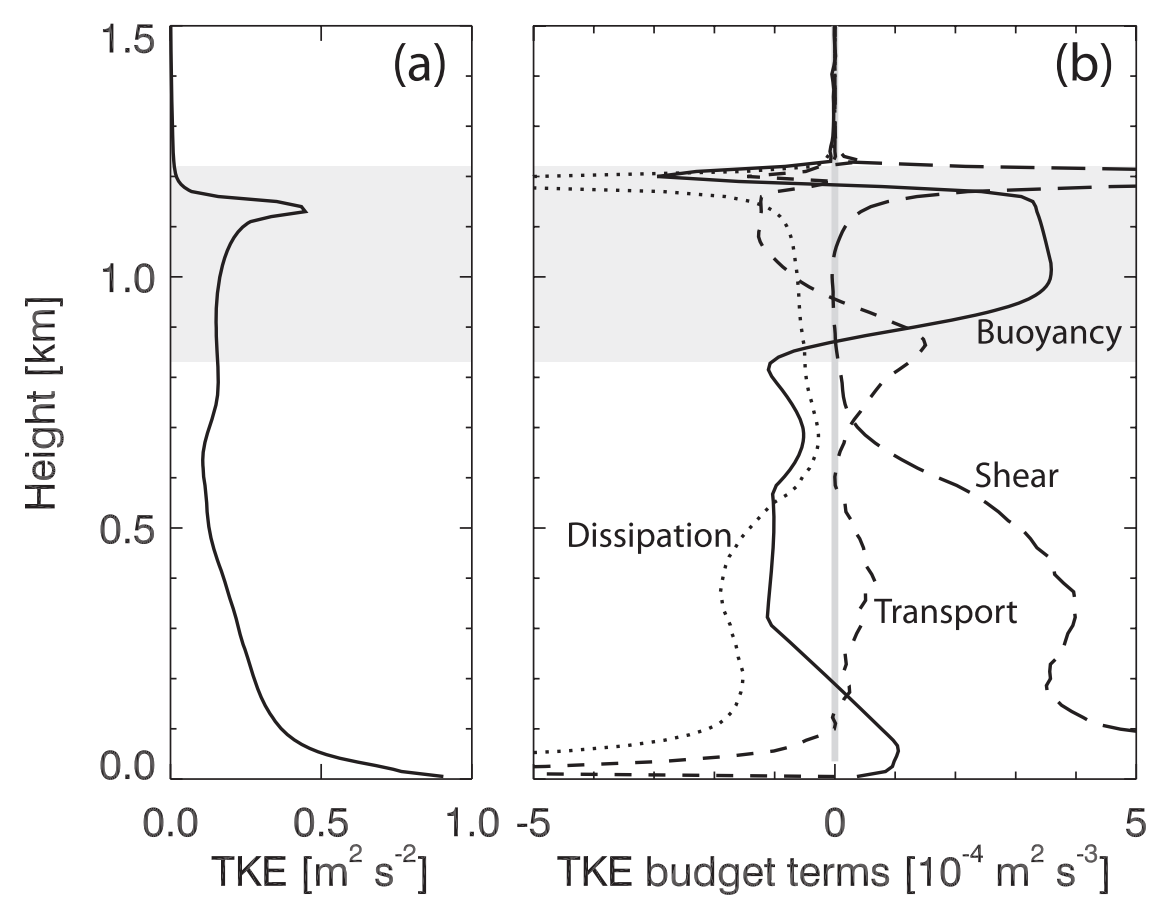

FIG. 12. Mean profiles of (a) TKE and (b) TKE budget terms, calculated over the last simulation hour $(5-6 \mathrm{~h})$. The region of light gray indicates the mean cloud layer.

Rogers (1996), who found that convective scalings fail when shear production of TKE substantially exceeds buoyancy production.

We note that the TKE budget is not completely consistent with the Eulerian framework used in the simulations. Formally, the TKE budget should include TKE advection terms imposed from the large scale. What the TKE budget represents, then, is the balance of processes internal to the boundary layer that generate and dissipate TKE. The budget serves as a tool to gauge the relative importance of these terms.

Recognizing the role of shear production in the TKE budget, we attempted to improve on (5) by evaluating several scalings that incorporated both buoyancy and shear. Conzemius and Fedorovich (2006) give a nice summary of some of these scalings, which generally apply to cloud-free convective boundary layers. Some of the approaches that take into account shear incorporate shear effects into a modified velocity scaling (e.g., Moeng and Sullivan 1994; Pino et al. 2003) based on both $w_{*}$ and $u_{*}$, which suggests that the shear-generation process is associated with the surface layer. To take into account shear across the inversion Conzemius and Fedorovich (2006) suggest a scaling such as $\left[\left(\Delta u^{2}+\Delta v^{2}\right) d z_{i} / d t\right]^{1 / 3}$, where $d z_{i} / d t$ is the entrainment rate and $\Delta u$ and $\Delta v$ represent "jumps" in the two wind components across the inversion. These scalings did not result in improvement to the scaling of (5) shown in Fig. 11. Certainly differences in shear production do not explain the spread between the cases since the shear in each case is largely similar.

To illustrate the role of shear we ran a simulation in which the initial wind field was set to zero, removing all shear arising from the mean wind. Figure 13 compares this no-shear simulation with the control experiment. As might be expected, the entrainment rate is dramatically smaller in the no-shear simulation ( 0.51 versus $0.84 \mathrm{~cm} \mathrm{~s}^{-1}$ ), leading to a shallower boundary layer depth over the course of the simulation. Liquid water in the no-shear simulation is greater, chiefly because of the reduction of entrainment of warm air that raises the saturation mixing ratio and thins the cloud layer. For a similar reason, the vertical velocity variance $\overline{w^{\prime} w^{\prime}}$ is larger in the no-shear case since the entrainment of warm, free-tropospheric air has been reduced. The deep layer of negative skewness is consistent with boundary layers predominantly driven by cloud-top cooling.

\section{Summary and discussion}

Previous LES approaches to stratocumulus-topped boundary layers focused primarily on marine environments. We have presented a suite of simulations for a case of continental stratocumulus observed over the Southern Great Plains ARM site in northern Oklahoma and documented in MKS. The cloud system was sampled by a wide variety of instruments at the ACRF, including 

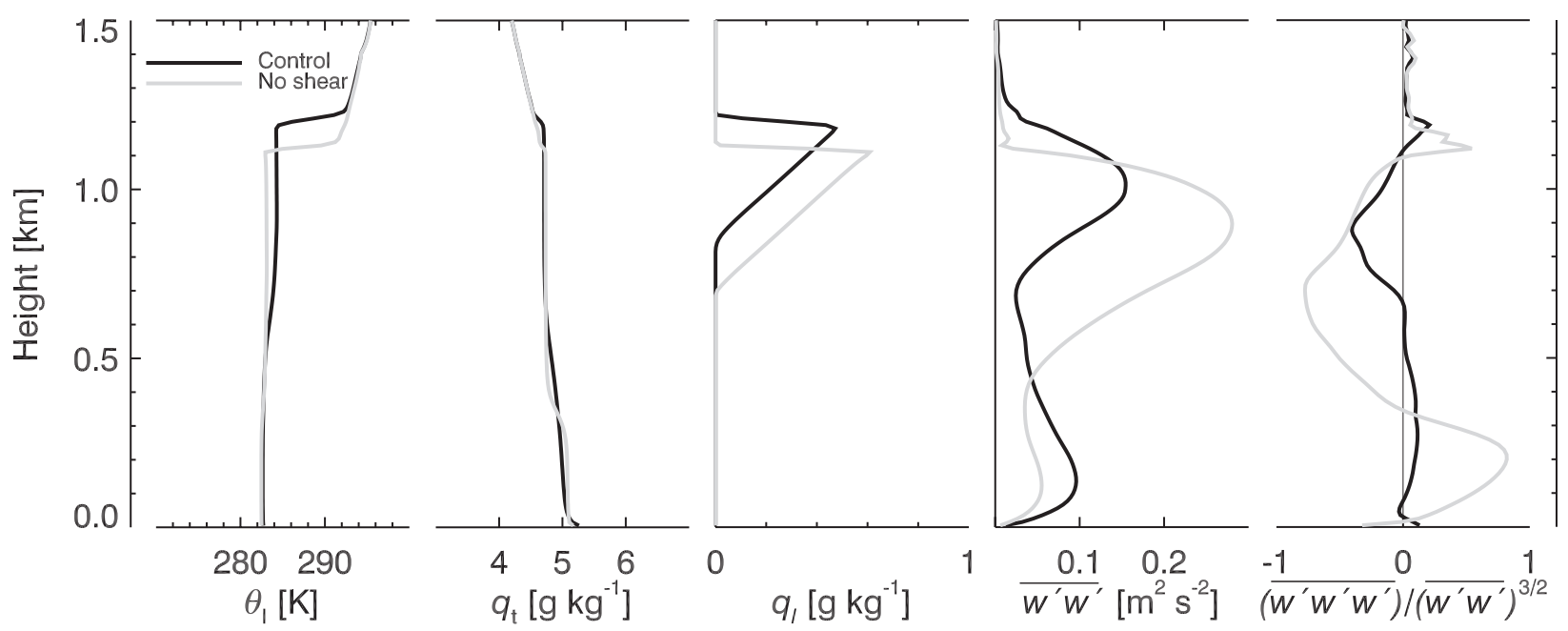

FIG. 13. Mean profiles of liquid water potential temperature $\left(\theta_{l}\right)$, total water $\left(q_{t}\right)$, liquid water mixing ratio $\left(q_{l}\right)$, vertical velocity variance $\left(\overline{w^{\prime} w^{\prime}}\right)$, and skewness $\left[\left(\overline{w^{\prime} w^{\prime} w^{\prime}}\right) /\left(\overline{w^{\prime} w^{\prime}}\right)^{3 / 2}\right]$, taken over the last hour of the simulation.

large-eddy observations from cloud radar. The observations, along with the RUC initial analysis, constrain the synoptic-scale forcings necessary for applying LES in an Eulerian framework.

LES results for the control simulation are for the most part consistent with the observations. The evolution of the LES thermodynamic and wind profiles is in reasonable agreement with the observational soundings. LES flux profiles are typical of an entraining stratocumulus layer-negative buoyancy flux at cloud top and near cloud base, both associated with entrainment; moistening and drying of the subcloud and cloud layers, respectively; and a bimodal distribution in vertical velocity variance, indicative of decoupling of the circulation between cloud and subcloud layers. The LES captures the turbulent intensity observed by the radar, as indicated by the vertical velocity variance. The negative skewness profile in the cloud layer is consistent with turbulence driven by cloud-top cooling. The LES profile contains the shallow transition layer near cloud top where skewness switches from negative to positive. This layer was not consistently present in MKS but has been observed in previous LEOs of stratocumulus.

One difference noted between this case and cloudy boundary layers in the maritime environment was that the continental case exhibited substantially weaker magnitudes of in-cloud turbulence (see Table 1 in MKS for a comparison with select marine stratocumulus cases). Our results suggest a plausible explanation why the buoyancy flux is negative over the bulk of the subcloud layer, acting to damp TKE generation. In the subcloud layer, shear generation predominates and is responsible for driving the subcloud layer turbulence, especially given the weak surface buoyancy flux. This deep layer of TKE shear generation is one significant difference relative to marine boundary layers and is likely a by-product of the sheared, baroclinic environment.

An objective of this study was to assess the relative sensitivity of LES to changes in forcing. Figures 7 and 8 summarize the dependence of cloud thickness to changes in temperature and moisture advection, vertical motion, and surface fluxes. Even modest changes in the synopticscale forcings, particularly the temperature and moisture advection, produce significant differences in LWP. However, the case is relatively insensitive to changes in surface fluxes of heat and moisture and to changes in subsidence divergence. Relative to marine stratocumulus, which are typically studied in a Lagrangian framework with relatively weak advective forcings, continental clouds associated with synoptic systems require highly constrained estimates of these advective terms. Our simplified forcings notwithstanding, this stratocumulus case was not accompanied by consistent subsidence and slowly varying advective forcings typical of a marine barotropic atmosphere. Instead, transient baroclinic structures complicate the forcing, even on the back side of the system, which appears on satellite imagery to be rather homogeneous. In this particular case, at least, cloud evolution is governed by advective forcing rather than the buoyancy reversal mechanisms so commonly associated with entrainment. This is an optimistic result for mesoscale, numerical weather prediction, and climate models since they resolve advection and synoptic-scale vertical motion better than they represent entrainment.

A standard entrainment scaling applied to the simulation ensemble serves as an additional point of comparison 
with marine stratocumulus cases. Our intent was not to develop a comprehensive entrainment closure, given the LES simulations, but rather to assess in a very simple manner how (or whether) simple boundary layer scalings would apply to continental stratocumulus. The entrainment rate was well correlated to mean boundary layer vertical velocity variance, but entrainment scalings based solely on convective velocity $w_{*}$ performed poorly. Improvement resulted when a portion of the radiative flux was incorporated into the entrainment relation. The TKE budget illustrated the importance of shear generation, but scalings that incorporated shear production of TKE were not noticeably better, most likely because shear was similar across all simulations. A simulation without shear was characterized by dramatically reduced entrainment $(\sim 40 \%)$, greater liquid water, and larger vertical velocity variance. Although shear production of TKE is very important, we speculate that the mediocre performance of typical entrainment scalings stems from the strongly decoupled circulation and difficulty in representing the twolayer dynamics using a simple convective velocity scale.

How representative is this case relative to other continental cases? This case took place under nocturnal conditions, and we suspect that these clouds behave differently during daytime when absorption of solar radiation will tend to stabilize the upper part of the cloud layer but enhance surface fluxes of heat and moisture. Kim et al. (2005) suggested that a wide variety of inversion structures can accompany continental stratocumulus. An observational climatology of the boundary layer and inversion structure accompanying SGP ACRF stratocumulus would greatly assist in generalizing these results. The idealized LES framework that we used is best suited for relatively slowly changing cloud and boundary layer properties, but may have drawbacks when applied to more unsteady conditions or when employed to represent larger-scale structures such as boundaries between cloudy and clear-sky conditions. A mesoscale modeling framework would be ideal for examining how continental stratocumulus behave in an environment with more realistic forcings, and our hypothesis that posits the relative importance of moisture and temperature advection could be straightforwardly examined.

Acknowledgments. Thanks to Marat Kharioutdinov for making the SAM model available to the scientific community. Thanks also to Kenneth Kehoe for his assistance with the ARM data archive. We appreciate the thorough reviews by Steve Krueger and an anonymous reviewer, which put the discussions on buoyancy reversal, scalings, and the TKE budget on more solid ground. Thanks to Adrian Lock for clarification of the scaling discussions in his papers. This investigation was supported by the University of Kansas General Research Fund Allocation 230211 and New Faculty Startup funds; by the Office of Science (BER), U.S. Department of Energy, Grant DE-FG02-05ER64062, as part of the Atmospheric Radiation Measurement Program; by ONR Grants N00014-05-1-0550, N00014-03-1-0304, and N0001408-10681; and by NOAA/Office of Oceanic and Atmospheric Research under NOAA-University of Oklahoma Cooperative Agreement NA17RJ1227, U.S. Department of Commerce. DS is partially supported by Vaisala Oyj. Some of the computing for this project was performed at the OU Supercomputing Center for Education and Research (OSCER) at the University of Oklahoma.

\section{REFERENCES}

Ackerman, A. S., M. P. Kirkpatric, D. E. Stevens, and O. B. Toon, 2004: The impact of humidity above stratiform clouds on indirect aerosol climate forcing. Nature, 432, 1014-1017.

_ , and Coauthors, 2009: Large-eddy simulations of a drizzling, stratocumulus-topped marine boundary layer. Mon. Wea. Rev., 137, 1083-1110.

Benjamin, S. G., and Coauthors, 2004a: An hourly assimilationforecast cycle: The RUC. Mon. Wea. Rev., 132, 495-518.

— G. A. Grell, J. M. Brown, T. G. Smirnova, and R. Bleck, 2004b: Mesoscale weather prediction with the RUC hybrid isentropic-terrain-following coordinate model. Mon. Wea. Rev., 132, 473-494.

Bony, S., and J. Dufresne, 2005: Marine boundary layer clouds at the heart of tropical cloud feedback uncertainties in climate models. Geophys. Res. Lett., 32, L20806, doi:10.1029/2005GL023851.

Bretherton, C. S., and Coauthors, 1999: An intercomparison of radiatively driven entrainment and turbulence in a smoke cloud, as simulated by different numerical models. Quart. J. Roy. Meteor. Soc., 125, 391-423.

_ P. N. Blossey, and J. Uchida, 2007: Cloud droplet sedimentation, entrainment efficiency, and subtropical stratocumulus albedo. Geophys. Res. Lett., 34, L03813, doi:10.1029/2006GL027648.

Brost, R. A., D. H. Lenschow, and J. C. Wyngaard, 1982: Marine stratocumulus layers. Part I: Mean conditions. J. Atmos. Sci., 39, 800-817.

Brown, A. R., and Coauthors, 2002: Large-eddy simulation of the diurnal cycle of shallow cumulus convection over land. Quart. J. Roy. Meteor. Soc., 128, 1075-1093.

Caldwell, P., and C. S. Bretherton, 2009: Large-eddy simulation of the diurnal cycle in southeast Pacific stratocumulus. J. Atmos. Sci., 66, 432-449.

Charlson, R. J., J. E. Lovelock, M. O. Andreae, and S. G. Warren, 1987: Oceanic phytoplankton, atmospheric sulphur, cloud albedo and climate. Nature, 326, 655-661.

Chlond, A., and A. Wolkau, 2000: Large-eddy simulation of a nocturnal stratocumulus-topped marine atmospheric boundary layer: An uncertainty analysis. Bound.-Layer Meteor., 95, $31-55$.

— F. Müller, and I. Sednev, 2004: Numerical simulation of the diurnal cycle of marine stratocumulus during FIRE-An LES and SCM modeling study. Quart. J. Roy. Meteor. Soc., 130, 3297-3321.

Conzemius, R. J., and E. Fedorovich, 2006: Dynamics of sheared convective boundary layer entrainment. Part II: Evaluation of 
bulk model predictions of entrainment flux. J. Atmos. Sci., 63, 1179-1199.

Deardorff, J. W., 1976: On the entrainment rate of a stratocumulustopped mixed layer. Quart. J. Roy. Meteor. Soc., 102, 563-582. , 1980a: Cloud top entrainment instability. J. Atmos. Sci., 37, 131-147.

— 1980b: Stratocumulus-capped mixed layers derived from a three-dimensional model. Bound.-Layer Meteor., 18, 495-527.

Field, P. R., and R. Wood, 2007: Precipitation and cloud structure in midlatitude cyclones. J. Climate, 20, 233-254; Corrigendum, 20, 5208 .

Fu, Q., and K. N. Liou, 1992: On the correlated $k$-distribution method for radiative transfer in nonhomogeneous atmospheres. J. Atmos. Sci., 49, 2139-2156.

— of cirrus clouds. J. Atmos. Sci., 50, 2008-2025.

Gerber, H., G. Frick, S. P. Malinowski, J.-L. Brenguier, and F. Burnet, 2005: Holes and entrainment in stratocumulus. J. Atmos. Sci., 62, 443-459.

Herman, G., and R. Goody, 1976: Formation and persistence of summertime arctic stratus clouds. J. Atmos. Sci., 33, 1537-1553.

James, D. G., 1959: Observations from aircraft of temperatures and humidities near stratocumulus clouds. Quart. J. Roy. Meteor. Soc., 85, 120-130.

Khairoutdinov, M. F., and Y. L. Kogan, 1999: A large-eddy simulation model with explicit microphysics: Validation against aircraft observations of a stratocumulus-topped boundary layer. J. Atmos. Sci., 56, 2115-2131.

— , and D. A. Randall, 2003: Cloud resolving modeling of the ARM summer 1997 IOP: Model formulation, results, uncertainties, and sensitivities. J. Atmos. Sci., 60, 607-625.

Kim, B.-G., S. A. Klein, and J. R. Norris, 2005: Continental liquid water cloud variability and its parameterization using Atmospheric Radiation Measurement data. J. Geophys. Res., 110, D15S08, doi:10.1029/2004JD005122.

Kollias, P., and B. Albrecht, 2000: The turbulence structure in a continental stratocumulus cloud from millimeter-wavelength radar observations. J. Atmos. Sci., 57, 2417-2434.

Lazarus, S. M., S. K. Krueger, and G. G. Mace, 2000: A cloud climatology of the Southern Great Plains ARM CART. J. Climate, 13, 1762-1775.

Lewellen, D. C., W. S. Lewellen, and S. Yoh, 1996: Influence of Bowen ratio on boundary layer cloud structure. J. Atmos. Sci., 53, 175-187.

Lilly, D. K., 1968: Models of cloud-topped mixed layers under a strong inversion. Quart. J. Roy. Meteor. Soc., 94, 292-309.

Lock, A. P., 1998: The parametrization of entrainment in cloudy boundary layers. Quart. J. Roy. Meteor. Soc., 124, 2729-2753.

__ and M. K. MacVean, 1999: The parametrization of entrainment driven by surface heating and cloud-top cooling. Quart. J. Roy. Meteor. Soc., 125, 271-299.

Lorenc, A. C., D. Barker, R. S. Bell, B. Macpherson, and A. J. Maycock, 1996: On the use of radiosonde humidity observations in mid-latitude NWP. Meteor. Atmos. Phys., 60, 3-17.

Mechem, D. B., Y. L. Kogan, and D. M. Schultz, 2010: Large-eddy observation of post-cold-frontal continental stratus. J. Atmos. Sci., 67, 3835-3853.

Medeiros, B., B. Stevens, I. M. Held, M. Zhao, D. L. Williamson, J. G. Olson, and C. S. Bretherton, 2008: Aquaplanets, climate sensitivity, and low clouds. J. Climate, 21, 4974-4991.

Moeng, C.-H., 1986: Large-eddy simulation of a stratus-topped boundary layer. Part I: Structure and budgets. J. Atmos. Sci., 43, 2886-2900
- 2000: Entrainment rate, cloud fraction, and liquid water path of PBL stratocumulus clouds. J. Atmos. Sci., 57, 3627-3643.

— buoyancy-driven boundary layer. J. Atmos. Sci., 47, 11491162.

_ , and P. P. Sullivan, 1994: A comparison of shear- and buoyancydriven planetary boundary layer flows. J. Atmos. Sci., 51, 9991022.

_ _ and Coauthors, 1996: Simulation of a stratocumulus-topped planetary boundary layer: Intercomparison among different numerical codes. Bull. Amer. Meteor. Soc., 77, 261-278.

Moyer, K. A., and G. S. Young, 1991: Observations of vertical velocity skewness within the marine stratocumulus-topped boundary layer. J. Atmos. Sci., 48, 403-410.

Neggers, R. A. J., B. Stevens, and J. D. Neelin, 2007: Variance scaling in shallow-cumulus-topped mixed layers. Quart. J. Roy. Meteor. Soc., 133, 1629-1641.

Nicholls, S., 1984: The dynamics of stratocumulus: Aircraft observations and comparisons with a mixed layer model. Quart. J. Roy. Meteor. Soc., 110, 783-820.

Pino, D., J. Vilà-Guerau de Arellano, and P. G. Duynkerke, 2003: The contribution of shear to the evolution of a convective boundary layer. J. Atmos. Sci., 60, 1913-1926.

Randall, D. A., 1980: Conditional instability of the first kind upsidedown. J. Atmos. Sci., 37, 125-130.

Rossow, W. B., and R. A. Schiffer, 1991: ISCCP cloud data products. Bull. Amer. Meteor. Soc., 72, 2-20.

Siems, S. T., C. S. Bretherton, M. B. Baker, S. S. Shy, and R. E. Breidenthal, 1990: Buoyancy reversal and cloudtop entrainment instability. Quart. J. Roy. Meteor. Soc., 116, 705-739.

Smolarkiewicz, P. K., and W. W. Grabowski, 1990: The multidimensional positive definite advection transport algorithm: Nonoscillatory option. J. Comput. Phys., 86, 355-375.

Stevens, B., 2000: Cloud transitions and decoupling in shear-free stratocumulus-topped boundary layers. Geophys. Res. Lett., 27, 2557-2560.

_ and precipitation in a buffered system. Nature, 461, 607-613, doi:10.1038/nature08281.

_ C.-H. Moeng, and P. P. Sullivan, 1999: Large-eddy simulations of radiatively driven convection: Sensitivities to the representation of small scales. J. Atmos. Sci., 56, 3963-3984.

— , and Coauthors, 2003: On entrainment rates in nocturnal marine stratocumulus. Quart. J. Roy. Meteor. Soc., 129, 34693493.

— , and Coauthors, 2005: Evaluation of large-eddy simulations via observations of nocturnal marine stratocumulus. Mon Wea. Rev., 133, 1443-1462.

Stull, R. B., 1988: An Introduction to Boundary Layer Meteorology. Kluwer Academic, 666 pp.

Tennekes, H., 1973: A model for the dynamics of the inversion above a convective layer. J. Atmos. Sci., 30, 558-567.

Tjernström, M., and D. P. Rogers, 1996: Turbulence structure in decoupled marine stratocumulus: A case study from the ASTEX field experiment. J. Atmos. Sci., 53, 598-619.

Turner, J. S., 1973: Buoyancy Effects in Fluids. Cambridge University Press, $367 \mathrm{pp}$.

vanZanten, M. C., P. G. Duynkerke, and J. W. M. Cuijpers, 1999: Entrainment parameterization in convective boundary layers. J. Atmos. Sci., 56, 813-838

Warren, S. G., C. J. Hahn, J. London, R. M. Chervi, and R. L. Jenne, 1986: Global distribution of total cloud cover and 
cloud type amounts over land. NCAR Tech. Note TN273+STR, 29 pp. + 200 maps. [Available from the National Center for Atmospheric Research, Boulder, CO 80307-3000.]

Williams, K. D., and M. J. Webb, 2009: A quantitative performance assessment of cloud regimes in climate models. Climate Dyn., 33, 141-157.

Wyant, M. C., C. S. Bretherton, H. A. Rand, and D. E. Stevens, 1997: Numerical simulations and a conceptual model of the stratocumulus to trade cumulus transition. J. Atmos. Sci., 54, 168-192.

Xie, S., and Coauthors, 2005: Simulations of midlatitude frontal clouds by single-column and cloud-resolving models during the Atmospheric Radiation Measurement March 2000 cloud intensive operational period. J. Geophys. Res., 110, D15S03, doi:10.1029/2004JD005119.
Xu, K.-M., and Coauthors, 2005: Modeling springtime shallow frontal clouds with cloud-resolving and single-column models. J. Geophys. Res., 110, D15S04, doi:10.1029/2004JD005153.

Yamaguchi, T., and D. A. Randall, 2008: Large-eddy simulation of evaporatively driven entrainment in cloud-topped mixed layers. J. Atmos. Sci., 65, 1481-1504.

Zhu, P., and B. Albrecht, 2003: Large eddy simulations of continental shallow cumulus convection. J. Geophys. Res., 108, 4453, doi:10.1029/2002JD003119.

,$- \ldots$, and J. Gottschalck, 2001: Formation and development of nocturnal boundary layer clouds over the southern Great Plains. J. Atmos. Sci., 58, 1409-1426.

- and Coauthors, 2005: Intercomparison and interpretation of single-column model simulations of a nocturnal stratocumulustopped marine boundary layer. Mon. Wea. Rev., 133, 2741-2758. 